Article

\title{
One-Pot Synthesis of 2,5-Diformylfuran from Fructose by Bifunctional Polyaniline-Supported Heteropolyacid Hybrid Catalysts
}

\author{
Shuqing Liu, Xing Fu, Jinhang Dai, Zhongbao Liu, Liangfang Zhu * and Changwei Hu * \\ Key Laboratory of Green Chemistry and Technology Ministry of Education, College of Chemistry, Sichuan \\ University, Chengdu, Sichuan 610064, China; liushuqing93@163.com (S.L.); fuxing1804@163.com (X.F.); \\ jinhang.dai@foxmail.com (J.D.); authenticscu@live.cn (Z.L.) \\ * Correspondence: zhulf@scu.edu.cn (L.Z.); changweihu@scu.edu.cn (C.H.); Tel.: +86-28-8541-5608 (L.Z.); \\ +86-28-85411105 (C.H.)
}

Received: 12 April 2019; Accepted: 10 May 2019; Published: 13 May 2019

\begin{abstract}
We report the preparation of bifunctional hybrid catalysts by supporting $\mathrm{H}_{3} \mathrm{PMo}_{12} \mathrm{O}_{40}$ $\left(\mathrm{PMo}_{12}\right)$ heteropolyacid (HPA) on polyaniline (PAN) or formyl-functionalized PAN (F-PAN) for the "one-pot" and "one-step" synthesis of 2,5-diformylfuran (DFF) from fructose via 5-hydroxymethylfurfural (HMF) intermediate. We show that the PMo $\mathrm{PM}_{12} \mathrm{HPA}$ is the main active species for both fructose dehydration and HMF oxidation owing to its Brønsted acidic and redox characters. However, the anchoring of $\mathrm{PMo}_{12}$ on PAN reduces the Brønsted acidity by acid-base interaction between protons in HPA and quinoid diimine structure in PAN, thereby reducing the dehydration performance. We demonstrate that the catalytic dehydration performance of the hybrid catalyst could be strengthened by grafting formyl groups on PAN before HPA anchoring. The highest DFF yield of $76.7 \%$ is obtained by conducting the "one-pot" reaction over the $40-\mathrm{PMo}_{12} / \mathrm{F}_{3}-\mathrm{PAN}$ catalyst at $413 \mathrm{~K}$ for $7 \mathrm{~h}$ in air, wherein the side-reactions of fructose or HMF degradation and HMF rehydration have been significantly reduced. This hybrid catalyst is reusable without significant activity loss, highlighting the designing of stable inorganic-organic hybrid catalysts for producing valuable hexose-derived platform chemicals.
\end{abstract}

Keywords: 2,5-diformylfuran; one-pot reaction; bifunctional catalysis; inorganic-organic hybrid catalysts; polyaniline

\section{Introduction}

The abundant and renewable biomass resource has been regarded as an ideal alternative to replace non-renewable fossil resources for producing value-added fine chemicals and liquid fuels [1]. So far, various value-added chemicals have been produced from cellulosic biomass [2-5]. Among others, 2,5-diformylfuran (DFF), the partially oxidized product from 5-hydroxymethylfurfural $(\mathrm{HMF})$, is considered as one of the most promising platform molecules owing to its broad potential as an intermediate for pharmaceuticals, fungicides, macrocyclic ligands, and as a cross-linker or monomer for novel polymeric materials [6,7]. Despite the high DFF yields ( $>90 \%)$ from the aerobic oxidation of pure HMF [8-18], the direct synthesis of DFF from fructose via HMF as an intermediate is more attractive since the separation and purification of HMF is energy-intensive because of the unstable characteristic of HMF during the acid-catalyzed HMF production. Nowadays, the development of a facile and highly selective "one-pot" strategy for fructose-to-DFF conversion is challenging.

Fructose-to-DFF conversion is a tandem reaction involving fructose-to-HMF dehydration over acid sites and subsequent HMF-to-DFF oxidation over redox sites (Scheme 1). However, the water formed during the foregoing dehydration step decelerates the following oxidation step. 
Furthermore, the co-existence of acid sites, redox sites, and water in the catalytic system always leads to the generation of a large amount of by-products (i.e., formic acid (FA), levulinic acid (LA), and humins) from the oxidative-degradation/polymerization of fructose and rehydration/polymerization of HMF. Therefore, a popular "one-pot" and "two-step" method has been developed for fructose-to-DFF conversion, wherein the acid and redox catalysts were added stepwise, giving out high DFF yields ranging from $70 \%$ to $80 \%$ [19-21]. However, such a "two-step" method complicates the technological process when considering a potential industrial application. In this regard, a single bifunctional catalyst with both acid and redox sites is preferable to allow a "one-pot" and "one-step" route.

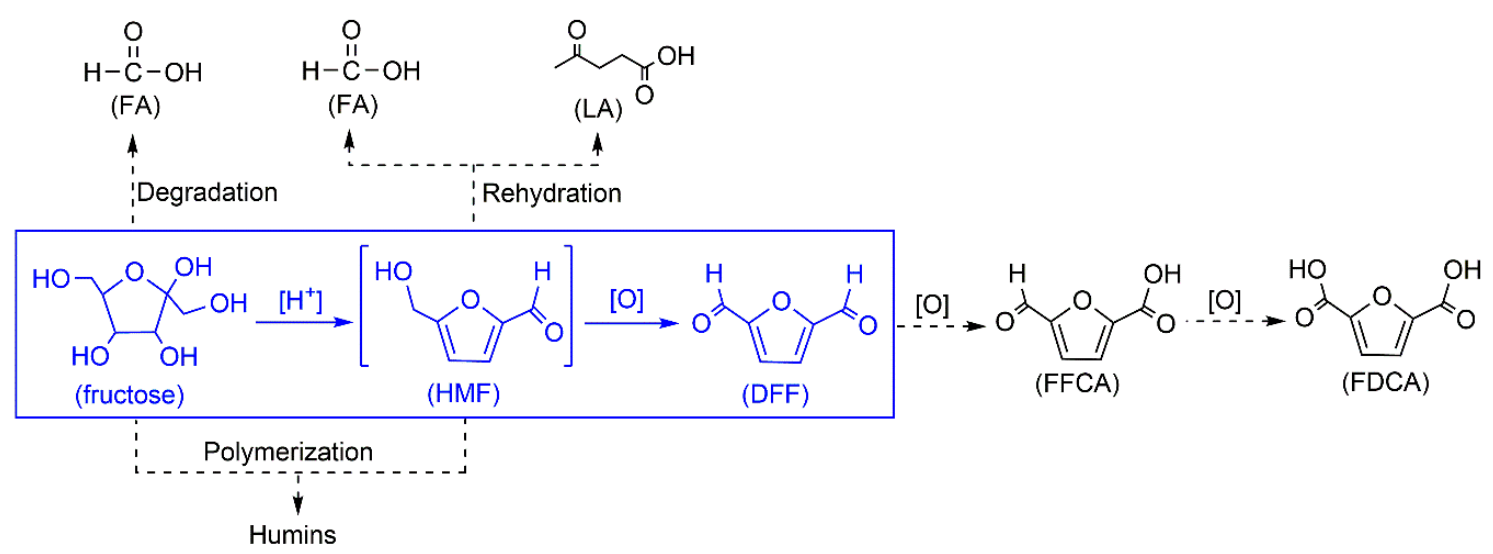

Scheme 1. Reaction scheme for the "one-pot" fructose-to-2,5-diformylfuran (DFF) transformation.

The reported bifunctional catalysts included the cesium salts of Mo- or Mo-V-containing Keggin heteropolyacids [22,23], graphene oxide [24], sulfonated amine-functionalized carbonaceous catalyst (CC-SO $\mathrm{SO}_{3} \mathrm{H}-\mathrm{NH}_{2}$ ) [25], Mo- or V-containing composite catalysts (e.g., f-Ce $\mathrm{Coo}_{1} \mathrm{O}_{\delta}$ [26], Mo-HNC [27], sulfonated $\mathrm{MoO}_{3}-\mathrm{ZrO}_{2}$ [28], $\mathrm{V}_{2} \mathrm{O}_{5} @ \mathrm{MOR}$ [29], and $\mathrm{V}-\mathrm{g}-\mathrm{C}_{3} \mathrm{~N}_{4}\left(\mathrm{H}^{+}\right)$[30]), and magnetic acid catalysts (e.g., $\mathrm{Fe}_{3} \mathrm{O}_{4} @ \mathrm{C}-\mathrm{SO}_{3} \mathrm{H}$ [31] and $\mathrm{WO}_{3} \mathrm{HO}-\mathrm{VO}$ (salten)- $\mathrm{SiO}_{2} @ \mathrm{Fe}_{3} \mathrm{O}_{4}$ [32]). Relatively higher DFF yields $(70 \sim 86 \%)$ have been obtained by conducting the fructose dehydration under a nitrogen atmosphere while subsequent oxidation under oxygen atmosphere [24-26,32-35], wherein the fructose oxidation could be reduced while a long reaction time of $11 \sim 24 \mathrm{~h}$ was required. In addition to the larger energy input, such a long reaction time also resulted in further oxidation of DFF to 5-formyl-2-furancarboxylic (FFCA) and/or 2,5-furandicarboxylic acid (FDCA) (Scheme 1), which undoubtedly increases the separation energy of the target product DFF. To lower the energy consumption for this "one-pot" and "one-step" fructose-to-DFF transformation, effective bifunctional solid catalysts are still needed.

An effective bifunctional catalyst is deemed to allow fast fructose dehydration and rapid HMF oxidation so as to minimize the possible parallel or tandem side-reactions from fructose and HMF, even in the presence of water. Among others, the Mo-containing catalysts have exhibited higher selectivity for fructose dehydration without nitrogen protection during the fructose-to-DFF conversion owing to the moderate redox performance of Mo-containing species [22,27,36]. The anchoring of Mo-containing active species onto a suitable organic "support" might retain their high selectivity while endowing an extra catalytic performance derived from the organic "support". Notably, polyaniline (PAN) has recently received particular interest in catalytic applications as a heterogeneous organic support owing to its facile synthesis, air-stable performance, good dispersion of active species, and the pseudo-homogeneous character in organic solvents [20,37-44]. In our group, we found that the functionalized PANs exhibited promising catalytic performance towards the dehydration of fructose into furans [45-47]. Considering the advantages and characteristics of PAN, we are expecting to incorporate the Mo-involved redox sites into the PAN "supports" such that the bifunctions of oxidation and dehydration could be combined, and even strengthened in a single inorganic-organic hybrid catalyst. Despite the heterogeneity of the hybrid catalyst, the catalytic performance for the tandem 
fructose-to-HMF dehydration and HMF-to-DFF oxidation are expected to be promoted in one-pot whereas the side reactions might be alleviated as much as possible.

In this work, we report the preparation of bifunctional inorganic-organic hybrid catalysts by supporting keggin-type $\mathrm{H}_{3} \mathrm{PMo}_{12} \mathrm{O}_{40}\left(\mathrm{PMo}_{12}\right)$ heteropolyacid (HPA) on PAN or formyl-functionalized PAN (F-PAN) for the "one-pot" and "one-step" synthesis of DFF from fructose. The morphology, composition, structure, and thermostability of the as-prepared $\mathrm{PMo}_{12} / \mathrm{PAN}$ and $\mathrm{PMo}_{12} / \mathrm{F}-\mathrm{PAN}$ catalysts are characterized by transmission electron microscope (TEM), scanning electron microscope (SEM)/energy dispersive X-ray spectroscopy (EDX) mapping, inductively coupled plasma-atomic emission spectroscopy (ICP-AES), Fourier transform infrared spectroscopy (FTIR), x-ray diffraction (XRD), and thermogravimetric (TG) analysis. The catalytic performances and reusability of these hybrid catalysts are studied for both HMF-to-DFF oxidation and the "one-pot" "one-step" fructose-to-DFF transformation.

\section{Results and Discussion}

\subsection{Preparation and Characterization of $x-P M o_{12} / P A N$ Catalysts}

The Keggin-type $\mathrm{PMo}_{12} \mathrm{HPA}$ was synthesized according to the literature [48], and the formation of the Keggin structure was confirmed by FTIR and XRD spectra (Figure S1). The sulfates of PAN were synthesized by oxidative polymerization of aniline with ammonium persulfate in dilute aqueous sulfuric acid at $278 \mathrm{~K}[45,49]$. The "support" PAN was then synthesized by deprotonating the PAN sulfates with aqueous ammonia at room temperature. The FTIR spectrum of PAN (Figure 1a, i) illustrated the formation of para-polymerized PAN owing to the appearance of the characteristic band centered at $826 \mathrm{~cm}^{-1}$ assigned to the $\mathrm{C}-\mathrm{H}$ out-of-plane bending in the 1,4-disubstituted ring structure of PAN [50]. The IR bands centered at 1495 and $1588 \mathrm{~cm}^{-1}$ respectively corresponded to the $C=C$ ring stretching vibration of benzenoid and quinone rings in PAN [51,52]. Besides, the IR band at $1160 \mathrm{~cm}^{-1}$ was assigned to the $C-C$ aromatic in-plane bending of PAN [53], and the band at $1295 \mathrm{~cm}^{-1}$ originated from the $\mathrm{C}-\mathrm{N}$ stretching vibration of the secondary aromatic amine $[54,55]$. The XRD pattern of PAN (Figure 1b, i) showed a typical amorphous structure of deprotonated PAN with a broad diffraction peak ranging from $2 \theta$ of $15 \sim 25^{\circ}[56,57]$.

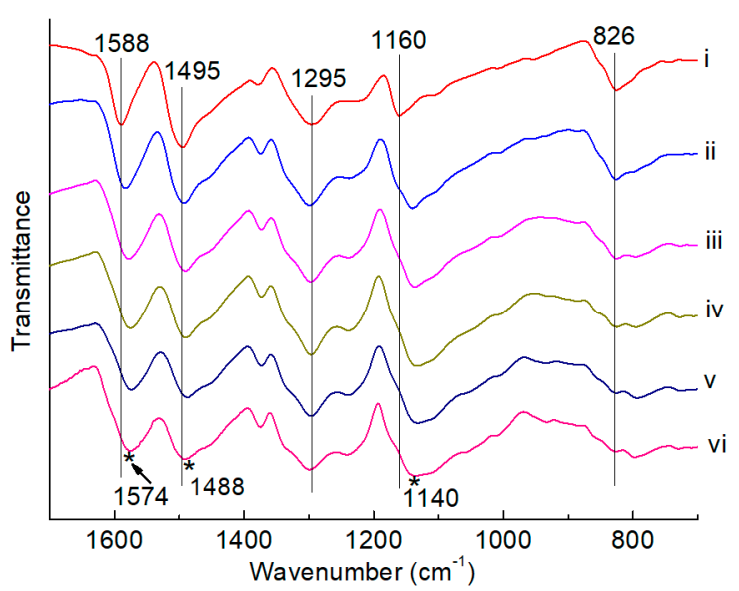

(a)

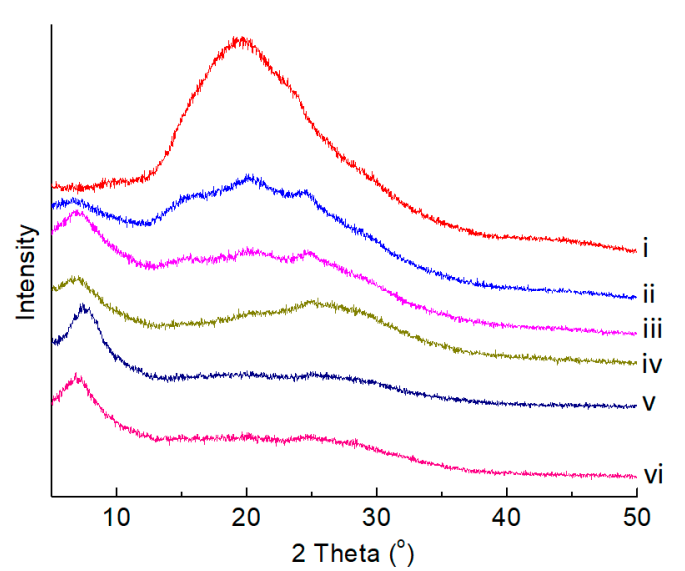

(b)

Figure 1. (a) FTIR spectra and (b) XRD patterns of the polyaniline (PAN) and $x-\mathrm{PMo}_{12} / \mathrm{PAN}$ catalysts. (i) PAN; (ii) 10-PMo ${ }_{12} / \mathrm{PAN}$; (iii) $20-\mathrm{PMo}_{12} / \mathrm{PAN}$; (iv) 30-PMo $12 / \mathrm{PAN}$; (v) 40- $\mathrm{PMo}_{12} / \mathrm{PAN}$; (vi) $50-\mathrm{PMo}_{12} / \mathrm{PAN}$.

A series of $x-\mathrm{PMo}_{12} / \mathrm{PAN}(x=10 \sim 50)$ catalysts were prepared by impregnating PAN in an aqueous ethanol solution $\left(V_{\mathrm{C} 2 \mathrm{H} 5 \mathrm{OH}} / V_{\mathrm{H} 2 \mathrm{O}}=1 / 1\right)$ containing $\mathrm{PMo}_{12} \mathrm{HPA}$, wherein $x$ represented the theoretical weight loading of HPA. The FTIR spectra of the $x$-PMo $\mathrm{PM}_{12} / \mathrm{PAN}$ catalysts (Figure 1a, ii vi) exhibited 
obvious shifts from 1495 to $1488 \mathrm{~cm}^{-1}$ and 1588 to $1574 \mathrm{~cm}^{-1}$, which were indicative of the protonation of PAN with HPA [58]. As proof, a broad and overlapping IR band at around $1100 \sim 1200 \mathrm{~cm}^{-1}$ appeared, which corresponded to the $-\mathrm{N}=$ quinoid $=\mathrm{N}-$ (electronlike band) stretching modes and often related to the protonated structure of PAN [59]. That is, the "support" PAN has been protonated with $\mathrm{PMo}_{12}$ HPA, most possibly via the acid-base interaction between the quinoid diimine structure in PAN and the protons in PMo 12 HPA (Scheme 2a). However, the characteristic IR bands of $\mathrm{PMo}_{12} \mathrm{HPA}$ centered at $1064,965,870$, and $787 \mathrm{~cm}^{-1}$ were obscure owing to their overlaps by the strong IR bands of PAN [60]. The XRD patterns of the $x$-PMo $\mathrm{PM}_{12} / \mathrm{PAN}$ catalysts (Figure $1 \mathrm{~b}$, ii $\sim v i$ ) showed a new and broad diffraction peak at $2 \theta=5 \sim 10^{\circ}$ assigned to the protonated PAN structure with increasing HPA loadings [56], thereby further confirming the anchoring of HPA on PAN. Nevertheless, these hybrid catalysts are still in amorphous structures. The ICP-AES analysis of the $x-\mathrm{PMo}_{12} / \mathrm{PAN}$ catalysts revealed that the actual HPA loading on the hybrid catalysts ranged from 8.4 to $38.5 \mathrm{wt} . \%$ (Table 1, entry 1 5). The absence of typical diffraction peaks of $\mathrm{PMo}_{12} \mathrm{HPA}$ on the XRD patterns of the as-prepared $x$ - $\mathrm{PMo}_{12} / \mathrm{PAN}$ catalysts was indicative of the good dispersion of HPA on the $x-\mathrm{PMo}_{12} / \mathrm{PAN}$ catalysts, which might benefit from the site-to-site acid-base interaction during HPA anchoring. As proof, we observed the morphologies of PAN and 40-PMo 12 /PAN catalyst by TEM (Figure S2), and found that they both existed in a sheet shape. Although no characteristic aggregation of HPA crystal was observed on the TEM and SEM images of the $40-\mathrm{PMo}_{12} / \mathrm{PAN}$ catalyst, the EDX-mapping of this catalyst strongly revealed the well-dispersion of HPA on the organic PAN support (Figure 2).

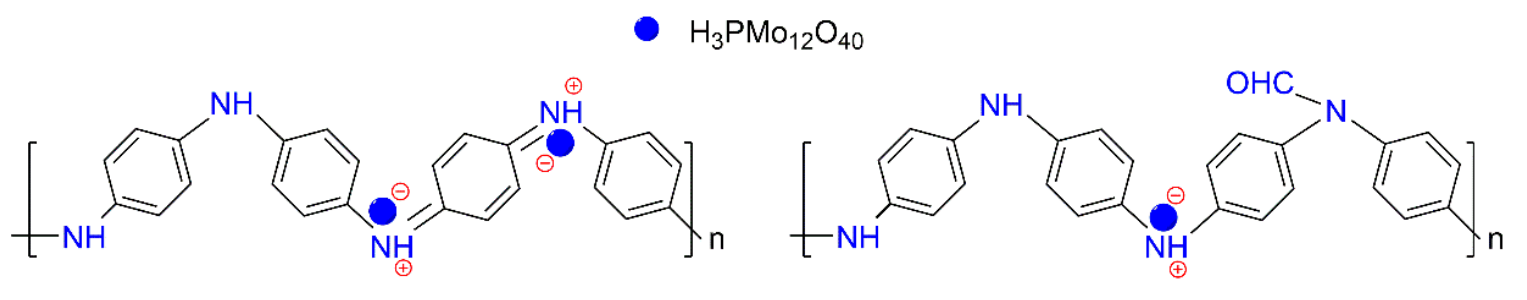

(a)

(b)

Scheme 2. Possible structures of (a) $\mathrm{PMo}_{12} / \mathrm{PAN}$, and (b) $\mathrm{PMo}_{12} / \mathrm{F}-\mathrm{PAN}$ catalysts. The $\mathrm{PMo}_{12}$ heteropolyacid (HPA) interacts with the organic supports by site-to-site acid-base interaction between the quinoid diimine structure in PAN (or F-PAN) and the protons in $\mathrm{PMo}_{12} \mathrm{HPA}$.

Table 1. Catalytic performance of several $\mathrm{PMo}_{12}$-containing catalysts in the aerobic oxidation of 5-hydroxymethylfurfural (HMF) to $\mathrm{DFF}^{\mathrm{a}}$.

\begin{tabular}{|c|c|c|c|c|c|}
\hline Entry & Cat. & $\begin{array}{l}\text { Actual Loading of } \\
\text { HPA (wt. } \% \text { ) }\end{array}$ & $\begin{array}{c}\text { Conv. } \\
(\mathrm{mol} \%)^{c}\end{array}$ & $\begin{array}{c}\mathrm{Y}_{\mathrm{DFF}} \\
(\mathrm{mol} \%)^{\mathrm{c}}\end{array}$ & $\begin{array}{c}\text { Carbon Balance } \\
(\mathrm{mol} \%)^{c}\end{array}$ \\
\hline 1 & $10-\mathrm{PMo}_{12} / \mathrm{PAN}$ & 8.4 & $56.5(13.1)$ & $53.6(12.3)$ & $97.1(99.2)$ \\
\hline 2 & $20-\mathrm{PMo}_{12} / \mathrm{PAN}$ & 15.6 & $75.6(15.0)$ & $74.9(14.7)$ & $99.3(99.7)$ \\
\hline 3 & $30-\mathrm{PMo}_{12} / \mathrm{PAN}$ & 26.2 & $96.5(16.1)$ & $91.5(15.2)$ & $95.0(99.1)$ \\
\hline 4 & $40-\mathrm{PMo}_{12} / \mathrm{PAN}$ & 31.3 & $97.2^{\mathrm{d}}(33.2)$ & $94.0^{\mathrm{e}}(31.6)$ & $96.8(98.4)$ \\
\hline 5 & $50-\mathrm{PMo}_{12} / \mathrm{PAN}$ & 38.5 & $100.0(26.6)$ & $91.2(24.7)$ & $91.2(98.1)$ \\
\hline $6^{f}$ & $\mathrm{PMo}_{12} \mathrm{HPA}$ & - & 100.0 & 96.0 & 96.0 \\
\hline $7 \mathrm{~g}$ & PAN & - & 21.0 & 14.4 & 93.4 \\
\hline $8^{h}$ & $40-\mathrm{PMo}_{12} / \mathrm{F}_{3}-\mathrm{PAN}$ & 30.6 & 60.0 & $58.4^{\mathrm{i}}$ & 98.4 \\
\hline
\end{tabular}

${ }^{a}$ Reaction conditions: $35 \mathrm{mg} \mathrm{HMF}, 30 \mathrm{mg}$ catalyst, $1 \mathrm{~mL}$ DMSO, $433 \mathrm{~K}, 4 \mathrm{~h}$, in air. ${ }^{\mathrm{b}}$ Actual $\mathrm{PMo}_{12}$ loadings obtained by ICP-AES analysis. ${ }^{c}$ The values in parentheses represent the data obtained after $1 \mathrm{~h}$ 's reaction. ${ }^{\mathrm{d}}$ The conversions of HMF were all $100 \%$ for the second, third, and fourth catalytic runs. ${ }^{e}$ The yields of DFF were $94.7 \%, 93.5 \%$, and $94.1 \%$, respectively, for the second, third, and fourth catalytic runs. ${ }^{\mathrm{f}} 9 \mathrm{mg} \mathrm{PMo}_{12}$ HPA was used. $\mathrm{g} 21 \mathrm{mg}$ PAN was used. ${ }^{\mathrm{h}} 5 \mathrm{mg}$ 40-PMo $\mathrm{PM}_{12} / \mathrm{F}_{3}-\mathrm{PAN}$ was used as a catalyst in the presence of water $(13.5 \mathrm{mg}) .{ }^{\mathrm{i}} \mathrm{FA}(1.5 \mathrm{~mol} \%)$ was generated as a by-product. 

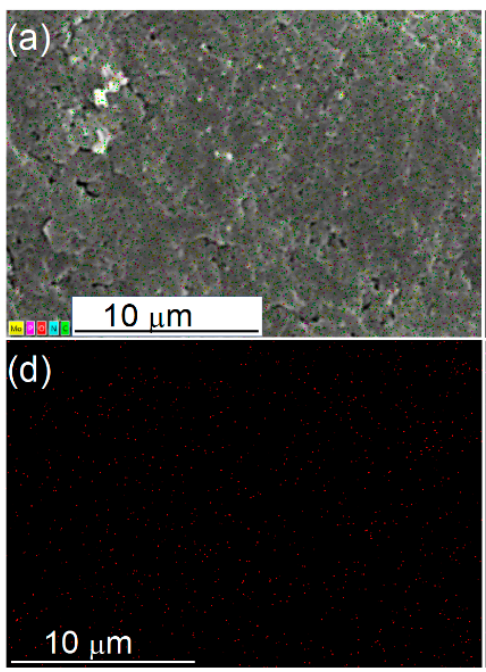

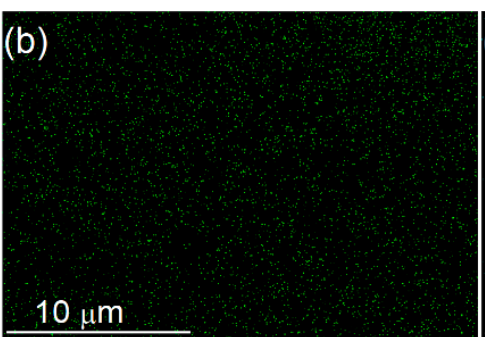

(e)

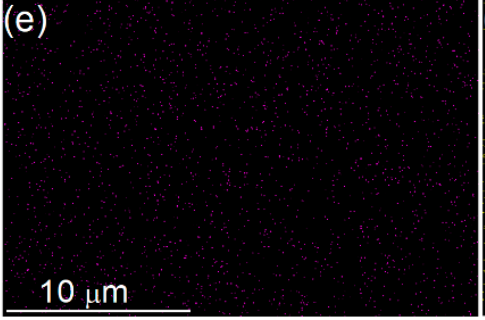

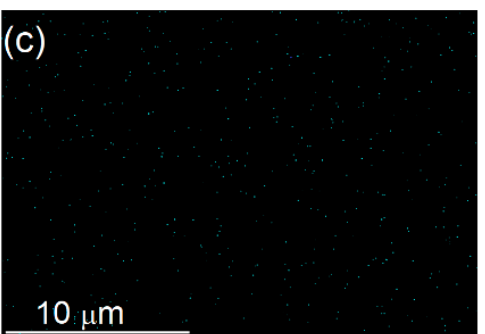

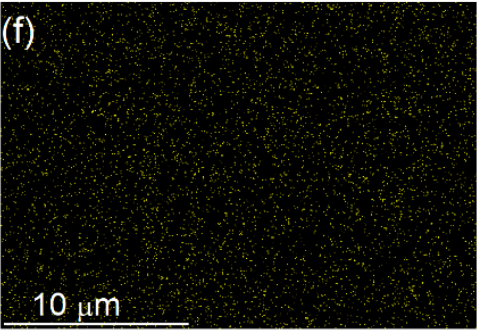

Figure 2. SEM/EDX-mapping of the 40-PMo $\mathrm{PM}_{12} / \mathrm{PAN}$ catalyst. (a) SEM photo, (b) C element, (c) N element, (d) O element, (e) P element, and (f) Mo element.

\subsection{Aerobic Oxidation of HMF to DFF over $x$-PMo 12 $_{2} / P A N$ Catalysts}

The catalytic performance of the $x-\mathrm{PMo}_{12} / \mathrm{PAN}$ catalysts in the aerobic oxidation of HMF to DFF at $433 \mathrm{~K}$ for $1 \mathrm{~h}$ and $4 \mathrm{~h}$ is depicted in Table 1 . After $1 \mathrm{~h}$ 's reaction, both the HMF conversion and the DFF yield increased with an increase of the $\mathrm{PMo}_{12}$ loadings from $8.4 \mathrm{wt} . \%\left(10-\mathrm{PMo}_{12} / \mathrm{PAN}\right)$ to $31.3 \mathrm{wt} . \%$ $\left(40-\mathrm{PMo}_{12} / \mathrm{PAN}\right.$ ) (entry $\left.1 \sim 4\right)$, reaching the maximum values at $33.2 \mathrm{~mol} \%$ and $31.6 \mathrm{~mol} \%$, respectively. However, a further increase of the HPA loading to $38.5 \mathrm{wt} . \%$ over $50-\mathrm{PMo}_{12} / \mathrm{PAN}$ catalyst resulted in the decrease of both HMF conversion (26.6 mol\%) and DFF yield (24.7 mol\%) (entry 5), possibly owing to the aggravation of humins generation as a result of the increase of Brønsted acidity on the hybrid catalyst. The prolonging of the reaction time to $4 \mathrm{~h}$ gave similar product distributions, wherein a maximum DFF yield of $94.0 \mathrm{~mol} \%$ was obtained over the $40-\mathrm{PMo}_{12} / \mathrm{PAN}$ catalyst (entry 4 ). It was noted that neither FA and LA nor FFCA and FDCA were detected over all these hybrid catalysts. In all cases, the carbon balances were higher than $91.2 \%$, thereby representing a good catalytic performance of the $x-\mathrm{PMo}_{12} / \mathrm{PAN}$ catalysts for the aerobic oxidation of HMF to DFF. In contrast experiments, the aerobic oxidation of HMF over $\mathrm{PMo}_{12} \mathrm{HPA}$ at $433 \mathrm{~K}$ for $4 \mathrm{~h}$ produced a similar high DFF yield of $96.0 \mathrm{~mol} \%$ with complete conversion of HMF (entry 6), while the oxidation over PAN just led to a DFF yield of $14.4 \mathrm{~mol} \%$ with HMF conversion of $21.0 \mathrm{~mol} \%$ (entry 7). It was obvious that the loading of the $\mathrm{PMo}_{12} \mathrm{HPA}$ on PAN improved the catalytic performance of the hybrid catalysts for the HMF-to-DFF oxidation. However, the comparison of the performance enhancement revealed that the $\mathrm{PMo}_{12} \mathrm{HPA}$ was the main active species for HMF oxidation. Notably, the heterogeneous $40-\mathrm{PMo}_{12} / \mathrm{PAN}$ catalyst showed good reusability for aerobic oxidation of HMF to DFF in successive four catalytic runs with DFF yield and selectivity less than $93.5 \%$ (entry 4 ).

\subsection{One-pot and One-step Conversion of Fructose to DFF over 40-PMo $12 / P A N$ Catalyst}

The $\mathrm{PMo}_{12}$ HPA was itself a homogeneous inorganic catalyst for the tandem fructose-to-HMF dehydration and HMF-to-DFF oxidation due to the co-existence of Brønsted acid sites and redox $\mathrm{Mo}^{6+}$ species in structure [22]. However, the direct use of $\mathrm{PMo}_{12} \mathrm{HPA}$ in this one-pot reaction $(433 \mathrm{~K}, 4 \mathrm{~h})$ led to the generation of a large amount of FA $(28.0 \mathrm{~mol} \%)$ and small amount of furfural (FF, $3.5 \mathrm{~mol} \%)$ in addition to DFF (61.0 mol\%) (Table 2, entry 1). The anchoring of the PMo $\mathrm{PM}_{12} \mathrm{HPA}$ onto the PAN "support" resulted in the decreases of DFF yield to $49.6 \mathrm{~mol} \%$, FF yield to $1.6 \mathrm{~mol} \%$, and FA yield to $19.5 \mathrm{~mol} \%$ over $40-\mathrm{PMo}_{12} / \mathrm{PAN}$ (entry 2). Meanwhile, the carbon balance for this fructose-to-DFF transformation was decreased to $60.0 \sim 69.5 \mathrm{~mol} \%$ (entry 1 5). The loss of the product yields and the carbon balance might originate from the reduction of the Brønsted acidity of the hybrid catalyst owing to the acid-base interaction between the protons in HPA and the quinoid diimine structure in 
PAN. Although the catalytic performance of the fresh $40-\mathrm{PMo}_{12} / \mathrm{PAN}$ catalyst was relatively lower, the reuse of this catalyst in successive runs produced notably higher DFF yields ranging from 58 to $68 \mathrm{~mol} \%$ accompanying with the decrease of FA yield to about $9 \mathrm{~mol} \%$ (entry 3 5). To reveal the possible deactivation or activity strengthening of the $40-\mathrm{PMo}_{12} / \mathrm{PAN}$ catalyst during the recycling process, in contrast, experiments, the one-pot conversions of fructose were performed at $433 \mathrm{~K}$ for only $1 \mathrm{~h}$. The results shown in Table 2 also indicated the obvious increase of both HMF and DFF yields for the second, third, and fourth catalytic runs when compared with the first catalytic run, thereby strongly demonstrating the strengthening of the dehydration performance for the used $40-\mathrm{PMo}_{12} / \mathrm{PAN}$ catalysts. The FTIR spectrum (Figure S3a) of the used catalyst exhibited a new IR band centered at $1669 \mathrm{~cm}^{-1}$ originating from the stretching vibration of the aldehyde group, which was indicative of the possible absorption of intermediate HMF and product DFF, or the grafting of formyl groups on the diimine nitrogen of PAN during the fructose conversion [45]. The possibility of HMF and DFF absorption on the used catalyst was excluded because the FTIR spectra of the $40-\mathrm{PMo}_{12} / \mathrm{PAN}$ catalysts after interacting with HMF or DFF produced a different IR band at 1662 and $1664 \mathrm{~cm}^{-1}$ (Figure S3c,d), respectively. Furthermore, the FTIR spectrum of the $40-\mathrm{PMo}_{12} / \mathrm{PAN}$ catalyst after its interaction with formaldehyde under similar experimental conditions in the absence of fructose was similar to that of the used $40-\mathrm{PMo}_{12} / \mathrm{PAN}$ catalyst (Figure S3b), thereby demonstrating the occurrence of formyl grafting on the $40-\mathrm{PMo}_{12} / \mathrm{PAN}$ catalyst during the fructose-to-DFF transformation. As shown in Scheme S1, the formal grafting might occur on the quinone diimine site, resulting in the formation of an amide structure in the polymer chain [45]. Here, the formaldehyde was generated from the direct decomposition of fructose accompanied by the formation of FF [61,62].

Table 2. Catalytic performance of several catalysts in the "one-pot" and "one-step" conversion of fructose to DFF. ${ }^{\text {a }}$

\begin{tabular}{|c|c|c|c|c|c|c|c|}
\hline Entry & Cat. & $\begin{array}{c}\text { Actual } \\
\text { Loading of } \\
\text { HPA (wt. } \% \text { ) }\end{array}$ & $\begin{array}{c}\text { Conv. } \\
(\mathrm{mol} \%)^{c}\end{array}$ & $\underset{(\mathrm{mol} \%)^{\mathrm{c}}}{\mathrm{Y}_{\mathrm{HMF}}}$ & $\begin{array}{c}\mathrm{Y}_{\mathrm{DFF}} \\
(\mathrm{mol} \%)^{c}\end{array}$ & $\underset{(\mathrm{mol} \%)^{c}}{\mathrm{Y}_{\mathrm{FA}}}$ & $\begin{array}{l}\text { Carbon } \\
\text { Balance } \\
(\mathrm{mol} \%)^{c}\end{array}$ \\
\hline $1^{\mathrm{d}}$ & $\mathrm{PMo}_{12} \mathrm{HPA}$ & - & 100 & - & 61.0 & 28.0 & 65.7 \\
\hline 2 & $40-\mathrm{PMo}_{12} / \mathrm{PAN}$ & 31.3 & $100(96.5)$ & $2.9(21.2)$ & $49.6(23.9)$ & $19.5(8.4)$ & $55.8(48.1)$ \\
\hline $3^{e}$ & $40-\mathrm{PMo}_{12} / \mathrm{PAN}$ & 31.3 & $100(96.6)$ & $-(30.5)$ & $58.0(30.5)$ & $12.0(4.2)$ & $60.0(63.9)$ \\
\hline $4^{\mathrm{f}}$ & $40-\mathrm{PMo}_{12} / \mathrm{PAN}$ & 31.3 & $100(97.6)$ & $-(30.7)$ & $68.0(31.4)$ & $9.0(4.5)$ & $69.5(63.6)$ \\
\hline $5^{g}$ & $40-\mathrm{PMo}_{12} / \mathrm{PAN}$ & 31.3 & $100(96.5)$ & - (37.9) & $65.0(31.2)$ & $9.0(3.8)$ & $66.5(72.3)$ \\
\hline $6^{\mathrm{h}}$ & $40-\mathrm{PMo}_{12} / \mathrm{F}_{1}-\mathrm{PAN}$ & 19.6 & 100 & 36.5 & 42.3 & 3.1 & 79.3 \\
\hline $7^{\mathrm{h}}$ & $40-\mathrm{PMo}_{12} / \mathrm{F}_{2}-\mathrm{PAN}$ & 22.9 & 100 & 12.0 & 64.5 & 6.6 & 77.6 \\
\hline $8^{h}$ & $40-\mathrm{PMo}_{12} / \mathrm{F}_{3}-\mathrm{PAN}$ & 30.6 & 100 & 9.7 & 67.1 & 5.5 & 77.7 \\
\hline
\end{tabular}

a Reaction conditions: $45 \mathrm{mg}$ fructose, $30 \mathrm{mg}$ catalyst, $1 \mathrm{~mL}$ DMSO, $433 \mathrm{~K}, 4 \mathrm{~h}$, in air. ${ }^{\mathrm{b}}$ Actual $\mathrm{PMo}_{12}$ loadings obtained by ICP-AES analysis. ${ }^{c}$ The values in parentheses represent the data obtained after $1 \mathrm{~h}$ 's reaction. ${ }^{\mathrm{d}} 9 \mathrm{mg}$ $\mathrm{PMo}_{12}$ HPA was used. e The second catalytic run. ${ }^{\mathrm{f}}$ The third catalytic run. ${ }^{\mathrm{g}}$ The fourth catalytic run. ${ }^{\mathrm{h}} 5 \mathrm{mg}$ $40-\mathrm{PMo}_{12} / \mathrm{F}_{\mathrm{y}}-\mathrm{PAN}$ catalysts were used.

\subsection{Preparation and Characterization of $40-P M o_{12} / F_{y}-P A N$ Catalysts}

In order to enhance the stability of the hybrid catalyst during the fructose conversion, the "support" PAN was modified by treating with various amount of formaldehyde at $413 \mathrm{~K}$ for $2 \mathrm{~h}$ before anchoring with $\mathrm{PMo}_{12} \mathrm{HPA}$. The as-prepared solid powders were named $\mathrm{F}_{\mathrm{y}}-\mathrm{PAN}$ and characterized by FTIR spectra (Figure 3a, i iii), wherein the appearance of IR band centered at $1675 \mathrm{~cm}^{-1}$ suggested the successful grafting of formyl groups on PAN [45]. Moreover, the relative peak intensity of $1675 \mathrm{~cm}^{-1}$ to $820 \mathrm{~cm}^{-1}\left(I_{1675} / I_{820}\right)$ on the FTIR spectra could be used to represent the grafting level of the formyl groups on $\mathrm{F}_{\mathrm{y}}$-PAN, and $I_{1606} / I_{1502}$ could be used to evaluate the relative content of the quinoid diimine and benzene ring structure [54]. As shown in Table S1, the grafting of formyl groups on $\mathrm{F}_{\mathrm{y}}$-PAN resulted in the decrease of $I_{1606} / I_{1502}$ (entry 1 3) when compared with that on PAN (entry 4), which was consistent with our previous work that demonstrated that the formaldehyde modification of PAN led to the reduction of quinoid diimine structure to phenylenediamine structure on the polymer chain [45]. 
Besides, we found that the grafting level of the formyl groups on $\mathrm{F}_{\mathrm{y}}$-PAN decreased with increasing the amount of formaldehyde used for modification.

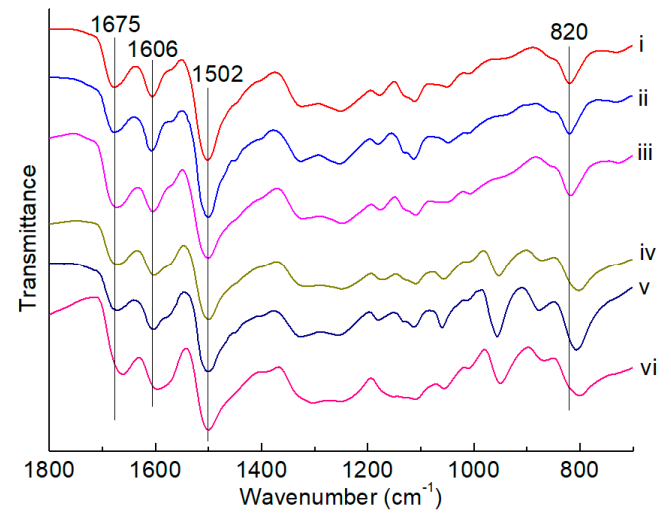

(a)

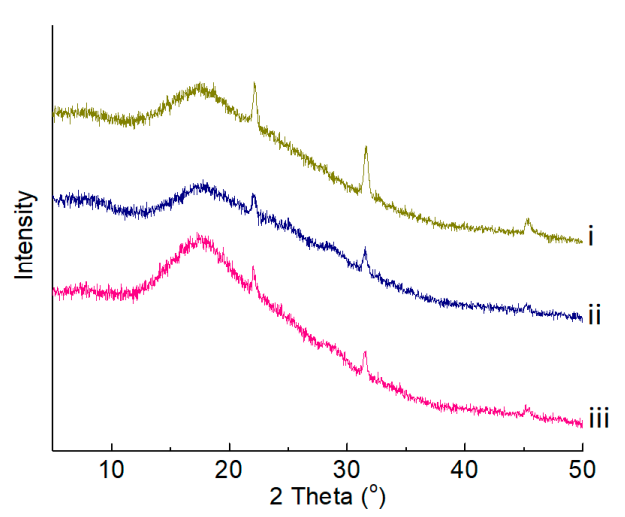

(b)

Figure 3. (a) FTIR spectra of $\mathrm{F}_{\mathrm{y}}-\mathrm{PAN}$ and $40-\mathrm{PMo}_{12} / \mathrm{F}_{\mathrm{y}}-\mathrm{PAN}$. (i) $\mathrm{F}_{1}-\mathrm{PAN}$, (ii) $\mathrm{F}_{2}-\mathrm{PAN}$, (iii) $\mathrm{F}_{3}-\mathrm{PAN}$, (iv) 40-PMo ${ }_{12} / \mathrm{F}_{1}-\mathrm{PAN}$, (v) 40-PMo $12 / \mathrm{F}_{2}-\mathrm{PAN}$, (vi) 40-PMo ${ }_{12} / \mathrm{F}_{3}$-PAN. (b) XRD patterns of $40-\mathrm{PMo}_{12} / \mathrm{F}_{\mathrm{y}}-\mathrm{PAN}$ catalysts. (i) $40-\mathrm{PMo}_{12} / \mathrm{F}_{1}-\mathrm{PAN}$; (ii) $40-\mathrm{PMo}_{12} / \mathrm{F}_{2}-\mathrm{PAN}$; (iii) $40-\mathrm{PMo}_{12} / \mathrm{F}_{3}-\mathrm{PAN}$.

After anchoring with $\mathrm{PMo}_{12} \mathrm{HPA}(40 \mathrm{wt} . \%)$, the actual HPA loadings on these $\mathrm{PMo}_{12} / \mathrm{F}_{\mathrm{y}}-\mathrm{PAN}$ catalysts varied, increasing from $19.6 \mathrm{wt} \%$ on $\mathrm{PMo}_{12} / \mathrm{F}_{1}-\mathrm{PAN}, 22.9 \mathrm{wt} . \%$ on $\mathrm{PMo}_{12} / \mathrm{F}_{2}-\mathrm{PAN}$, to $30.6 \mathrm{wt} . \%$ on $\mathrm{PMo}_{12} / \mathrm{F}_{3}$-PAN (Table 2), although the theoretical HPA loading was kept unchanged at $40 \mathrm{wt} \%$. These results indicated that the lower grafting level of formyl groups on $\mathrm{F}_{\mathrm{y}}-\mathrm{PAN}$ "support" was beneficial for loading the $\mathrm{PMo}_{12}$ HPA because both the formyl grafting and HPA anchoring occurred on the quinoid diimine sites. The possible chemical structure of the $\mathrm{PMo}_{12} / \mathrm{F}_{\mathrm{y}}-\mathrm{PAN}$ catalysts is shown in Scheme 2b. The FTIR spectra (Figure 3a, iv $\sim v i$ ) demonstrated that the formyl groups on $\mathrm{F}_{\mathrm{y}}$-PAN were stable during the HPA anchoring. The XRD patterns of the as-prepared $\mathrm{PMo}_{12} / \mathrm{F}_{\mathrm{y}}-\mathrm{PAN}$ catalysts (Figure $3 \mathrm{~b}$ ) revealed the partial crystallization of these hybrid catalysts owing to the appearance of sharp diffraction peaks at $2 \theta$ of $22^{\circ}$ and $32^{\circ}$ [56]. The reason for the formation of the partially crystallized species is unclear, requiring deep characterization in our future work. Nevertheless, the $\mathrm{PMo}_{12}$ species were still well-dispersed on the $\mathrm{F}_{\mathrm{y}}$-PAN "support" because no typical diffraction peaks assigning to crystallized $\mathrm{PMo}_{12} \mathrm{HPA}$ were observed on the XRD patterns and no obvious HPA crystals were observed on their TEM images (Figure S4). Meanwhile, this well-distribution of the $\mathrm{PMo}_{12}$ species was further supported by the EDX-mapping of the $\mathrm{PMo}_{12} / \mathrm{F}_{\mathrm{y}}-\mathrm{PAN}$ catalyst (Figure 4).
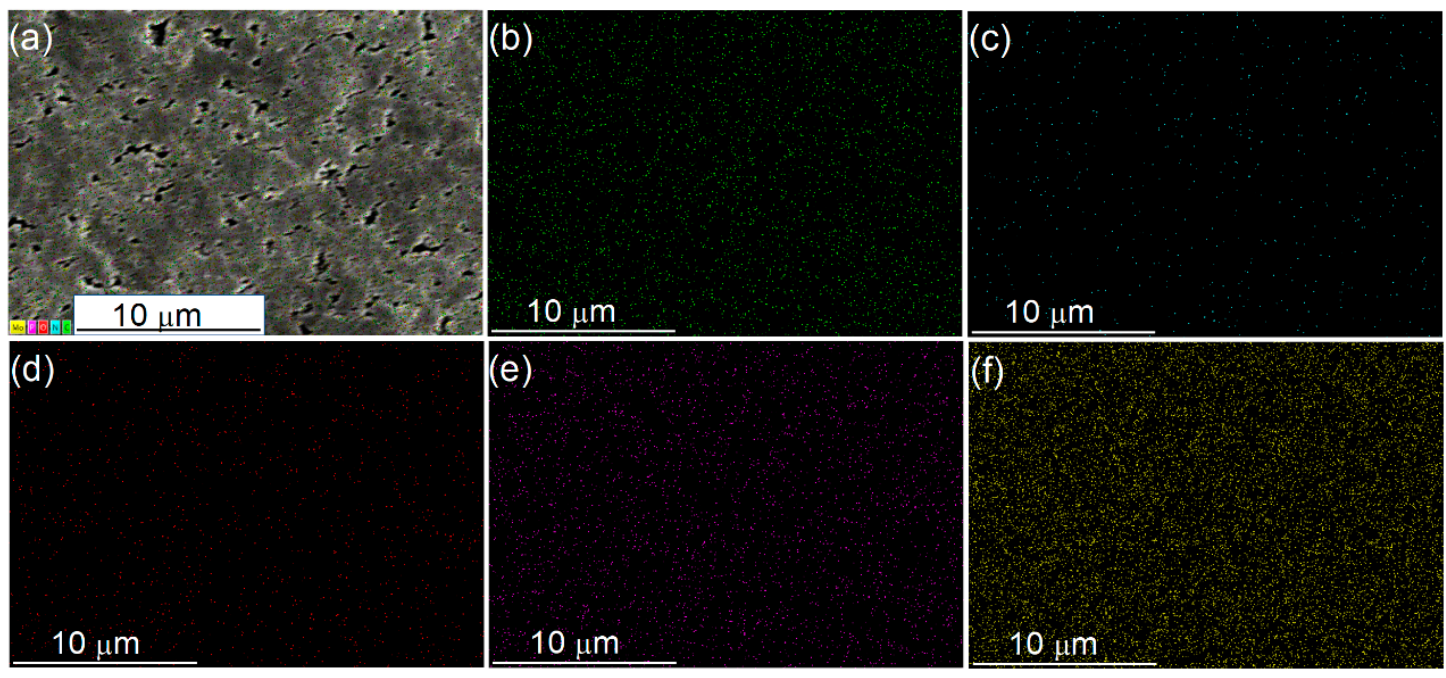

Figure 4. SEM/EDX-mapping of the $40-\mathrm{PMo}_{12} / \mathrm{F}_{3}-\mathrm{PAN}$ catalyst. (a) SEM photo, (b) C element, (c) $\mathrm{N}$ element, (d) O element, (e) P element, and (f) Mo element. 


\subsection{One-pot and One-step Conversion of Fructose to DFF over 40-PMo $12 / F_{y}-P A N$ Catalysts}

The catalytic performance of the $40-\mathrm{PMo}_{12} / \mathrm{F}_{\mathrm{y}}-\mathrm{PAN}$ catalysts in the direct conversion of fructose to DFF is depicted in Table 2 (entry 6 8). With increasing the HPA loadings, the DFF yields increased from $42.3 \mathrm{~mol} \%$ over $40-\mathrm{PMo}_{12} / \mathrm{F}_{1}-\mathrm{PAN}$ to $67.1 \mathrm{~mol} \%$ over $40-\mathrm{PMo}_{12} / \mathrm{F}_{3}-\mathrm{PAN}$. It was noted that the total yields of HMF and DFF, representing the total dehydration performance of the catalysts, were comparable for all $40-\mathrm{PMo}_{12} / \mathrm{F}_{\mathrm{y}}-\mathrm{PAN}$ catalysts, whereas higher than that of the $40-\mathrm{PMo}_{12} / \mathrm{PAN}$ catalyst ( $77.4 \mathrm{~mol} \%$ v.s. $52.5 \mathrm{~mol} \%$ ). The carbon balance was increased to approach $80.0 \mathrm{~mol} \%$ over these $40-\mathrm{PMo}_{12} / \mathrm{F}_{\mathrm{y}}-\mathrm{PAN}$ catalysts. That is, the grafting of formyl groups on PAN before anchoring the $\mathrm{PMo}_{12} \mathrm{HPA}$ promoted the catalytic dehydration performance of the $40-\mathrm{PMo}_{12} / \mathrm{F}_{\mathrm{y}}-\mathrm{PAN}$ hybrid catalysts, thereby illustrating that the $\mathrm{F}_{\mathrm{y}}-\mathrm{PAN}$ acts as a "support" for anchoring and dispersing $\mathrm{PMo}_{12}$ species as well as a co-catalyst for reinforcing the dehydration performance of the $\mathrm{PMo}_{12} / \mathrm{F}_{\mathrm{y}}-\mathrm{PAN}$ hybrid catalysts. Moreover, the production rates, expressed as ( $\mathrm{mol}$ of $\mathrm{DFF}) /\left(\mathrm{mol}\right.$ of $\left.\mathrm{PMo}_{12} \mathrm{HPA}\right)$, are comparatively shown in Table S2. The results revealed that the production rate of DFF on $40-\mathrm{PMo}_{12} / \mathrm{F}_{\mathrm{y}}-\mathrm{PAN}$ catalysts was higher than the $40-\mathrm{PMo}_{12} / \mathrm{PAN}$ catalyst, which strongly confirmed the reinforcement of the catalytic performance by the $\mathrm{F}_{\mathrm{y}}$-PAN support. In all cases, no LA was detected while FA formed with lower yields ranging from 3.1 to $6.6 \mathrm{~mol} \%$, which suggested that the FA came from direct degradation of fructose or HMF instead of from HMF rehydration. That is, the HMF rehydration during the "one-pot" and "one-step" fructose-to-DFF transformation over the $40-\mathrm{PMo}_{12} / \mathrm{F}_{\mathrm{y}}-\mathrm{PAN}$ hybrid catalysts has been completely inhibited whereas the fructose or HMF degradation to FA has been significantly reduced, thus avoiding the unfavorable impact of water on the tandem fructose-to-DFF reactions.

In addition, we found that the highest DFF yield of $99.9 \mathrm{~mol} \%$ could be achieved when conducting the aerobic oxidation of HMF over the $40-\mathrm{PMo}_{12} / \mathrm{F}_{3}-\mathrm{PAN}$ catalyst for $5 \mathrm{~h}$ (Figure $5 \mathrm{a}$ ). In another contrast experiment, the oxidation of $\mathrm{HMF}$ over the $40-\mathrm{PMo}_{12} / \mathrm{F}_{3}-\mathrm{PAN}$ catalyst in the presence of water resulted in a high DFF selectivity of $97.3 \%$, where a small amount of FA (1.5 mol\%) formed as the by-product from HMF degradation (Table 1 , entry 8 ). These results demonstrated that the $40-\mathrm{PMo}_{12} / \mathrm{F}_{3}-\mathrm{PAN}$ catalyst was highly selective towards the HMF-to-DFF oxidation, even in the presence of water.

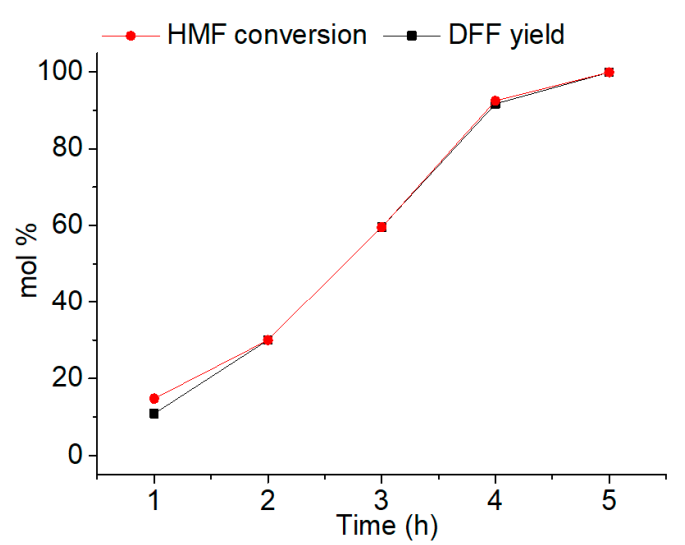

(a)

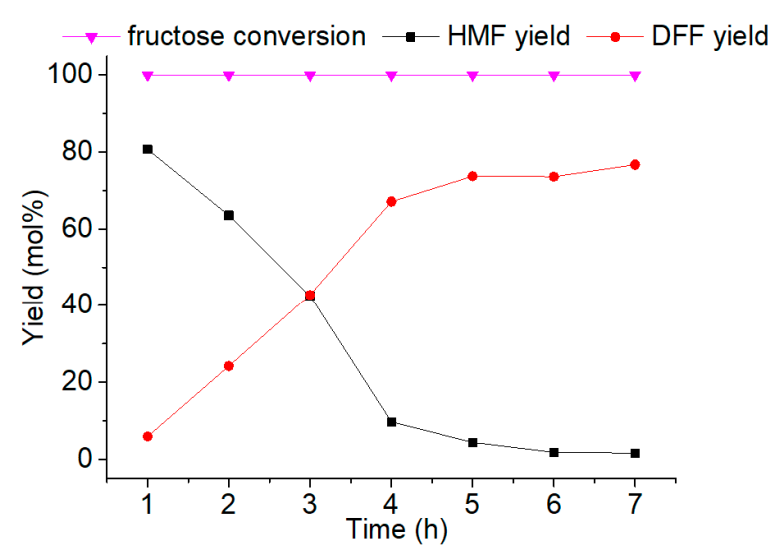

(b)

Figure 5. (a) Time profile for the aerobic oxidation of HMF to DFF over the $40-\mathrm{PMo}_{12} / \mathrm{F}_{3}-\mathrm{PAN}$ catalyst. (b) Time profile for the "one-pot" and "one-step" conversion of fructose to DFF over the 40-PMo ${ }_{12} / \mathrm{F}_{3}$-PAN catalyst. Reaction conditions: $35 \mathrm{mg} \mathrm{HMF}$ or $45 \mathrm{mg}$ fructose, $5 \mathrm{mg} 40-\mathrm{PMo}_{12} / \mathrm{F}_{3}-\mathrm{PAN}$ catalyst, $1 \mathrm{~mL}$ DMSO, $433 \mathrm{~K}$, in air.

Notably, over the bifunctional 40-PMo $12 / \mathrm{F}_{3}-\mathrm{PAN}$ catalyst, the DFF yields in the "one-pot" and "one-step" fructose-to-DFF transformation could be increased to $76.7 \mathrm{~mol} \%$ by prolonging the reaction time to $7 \mathrm{~h}$ (Figure $5 \mathrm{~b}$ ). This bifunctional hybrid catalyst produced higher or considerable DFF yields to the $\mathrm{Cs}_{3} \mathrm{HPMo}_{11} \mathrm{VO}_{40}$ [23], graphene oxide [24], f-Ceg $\mathrm{Mo}_{1} \mathrm{O}_{\delta}$ [26], sulfonated $\mathrm{MoO}_{3}-\mathrm{ZrO}_{2}$ [28], and $\mathrm{Ru} / \mathrm{H}$-beta [33] catalysts, especially by shortening the reaction time to $7 \mathrm{~h}$ (Table 3). Although the catalytic performance of our hybrid catalyst was relatively lower than those of the 
$\mathrm{V}_{2} \mathrm{O}_{5} @ \mathrm{MOR}(+\mathrm{HCl})$ [29], Au-Ru/rGO [34], and $\mathrm{Co} / \mathrm{Al}$ hydrotalcites [35] catalysts, the use of liquid acid catalyst and/or the switching of the reaction atmosphere have been avoided in our work. Significantly, this inorganic-organic hybrid catalyst showed higher activity for DFF formation when compared with our previously reported $\mathrm{Cs}_{0.5} \mathrm{H}_{2.5} \mathrm{PMo}_{12} \mathrm{O}_{40}$ catalyst because of the strengthening of the dehydration performance by the organic "support". Furthermore, the site time yield (STY) of DFF, expressed as (mol of DFF)/(g of catalyst)/h, are also compared in Table 3. The bifunctional hybrid catalyst exhibits higher STY than most of the reported catalysts except the $\mathrm{Cs}_{0.5} \mathrm{H}_{2.5} \mathrm{PMo}_{12} \mathrm{O}_{40}$ [22] and sulfonated $\mathrm{MoO}_{3}-\mathrm{ZrO}_{2}$ [28] catalysts, possibly due to the smaller amount of active sites in the hybrid catalyst.

Table 3. Catalytic performance comparison of the bifunctional hybrid catalyst with those reported in the literature for the "one-pot" fructose-to-DFF transformation.

\begin{tabular}{|c|c|c|c|c|c|c|c|c|}
\hline Entry & Catalyst & $\mathrm{T}(\mathrm{K})$ & $\begin{array}{l}\text { Time } \\
\text { (h) }\end{array}$ & $\begin{array}{c}\text { Conv. } \\
(\mathrm{mol} \%)\end{array}$ & $\begin{array}{c}\mathrm{Y}_{\text {HMF }} \\
(\mathrm{mol} \%)\end{array}$ & $\begin{array}{c}Y_{\mathrm{DFF}} \\
(\mathrm{mol} \%)\end{array}$ & $\begin{array}{l}\text { STY of DFF ( } \\
\left.10^{-3} \mathrm{~mol} / \mathrm{g} / \mathrm{h}\right)^{\mathrm{c}}\end{array}$ & Ref. \\
\hline 1 & $\mathrm{Cs}_{0.5} \mathrm{H}_{2.5} \mathrm{PMo}_{12} \mathrm{O}_{40}$ & 433 & 4 & 100 & 0.2 & 69 & 8.6 & [22] \\
\hline 2 & $\mathrm{Cs}_{3} \mathrm{HPMo}_{11} \mathrm{VO}_{40}$ & 393 & $2+6^{a}$ & 99 & 2 & 60 & 0.6 & [23] \\
\hline 3 & Graphene oxide & 413 & $2+22^{a}$ & $-b$ & $-b$ & 72 & 3.0 & [24] \\
\hline 4 & $\mathrm{f}-\mathrm{Ce}_{9} \mathrm{Mo}_{1} \mathrm{O}_{\delta}$ & 393 & $2+10^{a}$ & 100 & $-b$ & 74 & 0.7 & [26] \\
\hline 5 & $\begin{array}{l}\text { Sulfonated } \\
\mathrm{MoO}_{3}-\mathrm{ZrO}_{2}\end{array}$ & 423 & 10 & 100 & $-b$ & 74 & 8.2 & [28] \\
\hline 6 & $\begin{array}{c}\mathrm{V}_{2} \mathrm{O}_{5} @ \mathrm{MOR} \\
(+\mathrm{HCl})\end{array}$ & 393 & $4+12^{a}$ & 100 & 0.1 & 96 & 0.2 & [29] \\
\hline 7 & $\mathrm{Ru} / \mathrm{H}$-beta & 393 & 24 & 100 & $-b$ & 80 & 0.3 & [33] \\
\hline 8 & $\mathrm{Au}-\mathrm{Ru} / \mathrm{rGO}$ & 383 & $2+6^{a}$ & 100 & $-b$ & 86 & 2.7 & [34] \\
\hline 9 & $\begin{array}{c}\mathrm{Co} / \mathrm{Al} \\
\text { hydrotalcites }\end{array}$ & 393 & $2+6^{a}$ & 100 & $-b$ & 87 & 2.2 & [35] \\
\hline 10 & $\mathrm{PMo}_{12} / \mathrm{F}-\mathrm{PAN}$ & 433 & 7 & 100 & 1.6 & 76.7 & 5.5 & This work \\
\hline
\end{tabular}

Although about $1.5 \sim 3.0 \%$ of the $\mathrm{PMo}_{12}$ species leached from the $40-\mathrm{PMo}_{12} / \mathrm{F}_{3}-\mathrm{PAN}$ catalyst (Table S3), we found that the $40-\mathrm{PMo}_{12} / \mathrm{F}_{3}-\mathrm{PAN}$ hybrid catalyst could be reused for at least four catalytic runs with DFF yield no less than $63.0 \mathrm{~mol} \%$ for $4 \mathrm{~h}$ 's reaction(Figure 6a). In comparison, the recycling experiments were carried out for only $0.2 \mathrm{~h}$ or $1.0 \mathrm{~h}$ to investigate the possible deactivation of the $40-\mathrm{PMo}_{12} / \mathrm{F}_{3}-\mathrm{PAN}$ catalyst (Table S4). For the reaction of $0.2 \mathrm{~h}$, the fructose conversions were similar (41.9 43.5 mol\%) for the successive four catalytic runs with similar HMF yields ranging from $36.9 \mathrm{~mol} \%$ to $37.9 \mathrm{~mol} \%$ and a trace amount of DFF formed, which suggested a stable catalytic performance of the $40-\mathrm{PMo}_{12} / \mathrm{F}_{3}-\mathrm{PAN}$ catalyst for the fructose-to-HMF dehydration. In the meantime, the fructose conversion was performed with a smaller stirring speed of $50 \mathrm{rpm}$. A similar HMF yield of $37.7 \mathrm{~mol} \%$ was obtained as compared with that under a faster stirring speed of $400 \mathrm{rpm}$, thereby revealing the insignificance of the mass transfer limitation in the catalytic tests. Increasing the reaction time to 1.0 $\mathrm{h}$ resulted in the increase of the fructose conversion to nearly $100 \mathrm{~mol} \%$ with HMF formed as the major product and DFF as the minor product. This result indicated that the rate of fructose-to-HMF dehydration was very fast, whereas the oxidation was relatively slower. Nevertheless, the considerable total yields of HMF and DFF (70.0 75.6 mol\%) in the recycling tests for $1 \mathrm{~h}$ demonstrated the good reusability of the $40-\mathrm{PMo}_{12} / \mathrm{F}_{3}-\mathrm{PAN}$ catalyst during the recycling tests. Moreover, the heterogeneity of the hybrid catalyst could be ensured because the leached $\mathrm{PMo}_{12}$ species contributed little to the fructose-to-DFF conversion. Lower DFF yields of 4.9 5.0 mol\% were obtained by using the leached $\mathrm{PMo}_{12}$ species as the catalyst (Table S3). The FTIR spectra of the spent $40-\mathrm{PMo}_{12} / \mathrm{F}_{3}-\mathrm{PAN}$ catalysts after the first and fourth catalytic runs (Figure $6 \mathrm{~b}$ ) were similar to that of the fresh one, which illustrated the stability of the inorganic-organic hybrid catalyst under the experimental conditions. A further TG study of the fresh and spent $40-\mathrm{PMo}_{12} / \mathrm{F}_{3}-\mathrm{PAN}$ catalysts showed that both catalysts began to decompose at $598 \sim 620 \mathrm{~K}$ (Figure S5), which demonstrated the thermostability of the $40-\mathrm{PMo}_{12} / \mathrm{F}_{3}-\mathrm{PAN}$ catalyst under the experimental conditions. 


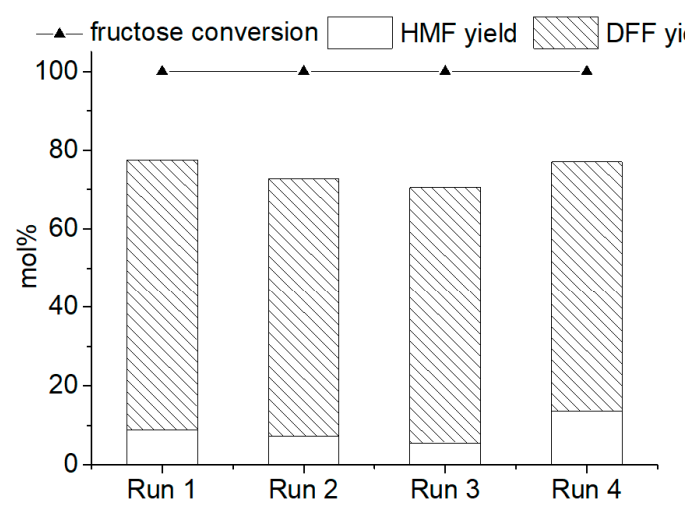

(a)

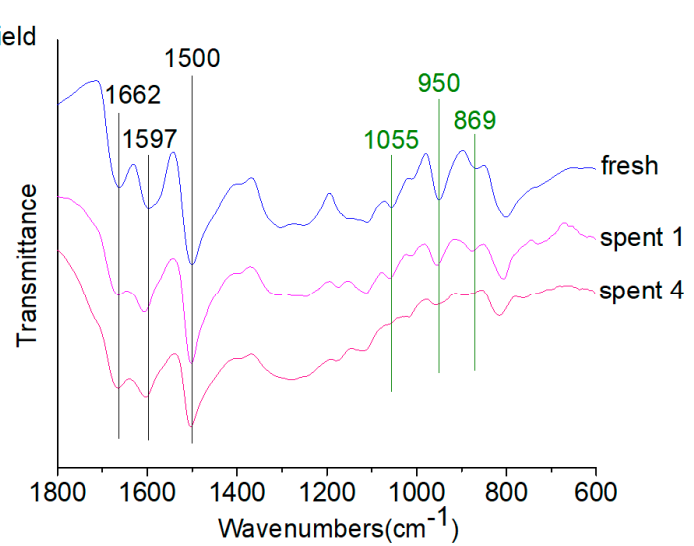

(b)

Figure 6. (a) Recycled use of 40-PMo $\mathrm{PM}_{12} / \mathrm{F}_{3}-\mathrm{PAN}$ catalyst in the "one-pot" and "one-step" fructose-to-DFF conversion. (b) FTIR spectra of the fresh and spent $40-\mathrm{PMo}_{12} / \mathrm{F}_{3}-\mathrm{PAN}$ catalysts. Spent 1 represents the used catalyst after the first catalytic run; Spent 4 represents the used catalyst after the fourth catalytic run. Reaction conditions: $45 \mathrm{mg}$ fructose, $30 \mathrm{mg}$ catalyst, $1 \mathrm{~mL} \mathrm{DMSO}, 433 \mathrm{~K}, 4 \mathrm{~h}$, in air.

\section{Materials and Methods}

\subsection{Materials}

HMF (98\%), DFF (98\%), LA (98\%), and FA (98\%) were purchased from J\&K chemical co., Ltd. (Beijing, China). Fructose (98\%), FFCA (>98\%), and FDCA (97\%) were purchased from Tokyo Chemical Industry (Tokyo, Japan). DMSO (99\%), sulfuric acid (98\%), formaldehyde (40 wt.\%), aqueous ammonia (25 28 wt.\%), and analytical reagent (AR) grade of ethyl ether, aniline, and ammonium persulfate were purchased from Kolong chemical company (Chengdu, China). $\mathrm{Na}_{2} \mathrm{HPO}_{4}$ and $\mathrm{Na}_{2} \mathrm{MoO}_{4}$ in $\mathrm{AR}$ grade were purchased from Chengdu Chemical Reagent Company (Chengdu, China) and Tianjin Chemical Reagent Company (Tianjin, China), respectively. Aniline was distilled before use. All of the other chemical reagents were used as purchased without further purification. Ultrapure water (resistance $=18.25 \mathrm{M} \Omega \mathrm{cm}^{-1}$ ) was used in all of our experiments.

\subsection{Methods}

\subsubsection{Catalyst Preparation}

The Keggin-type $\mathrm{PMo}_{12} \mathrm{HPA}$ was synthesized as follows: $\mathrm{Na}_{2} \mathrm{HPO}_{4}(74.0 \mathrm{~g} / \mathrm{L}, 100 \mathrm{~mL})$ and $\mathrm{Na}_{2} \mathrm{MoO}_{4}(295.0 \mathrm{~g} / \mathrm{L}, 200 \mathrm{~mL})$ were mixed and heated to boiling for $30 \mathrm{~min}$. After being cooled down to room temperature, the mixture was dropped slowly with concentrated $\mathrm{H}_{2} \mathrm{SO}_{4}$ with vigorous stirring until the $\mathrm{pH}$ of the mixture reached 2, giving out a yellow mixture containing $\mathrm{PMo}_{12} \mathrm{HPA}_{\text {. }}$ The $\mathrm{PMo}_{12}$ HPA was then extracted with ethyl ether $(300 \mathrm{~mL})$. After separation, a stream of air was passed through the heteropoly etherate layer (upper layer) to get the crude orange solid. This solid was then dissolved in a small amount of water, concentrated to the appearance of crystals in a vacuum desiccator, and allowed to be crystallized further. The resultant yellow solid powder was dried at $353 \mathrm{~K}$ for $10 \mathrm{~h}$.

PAN was prepared as follows: Freshly distilled aniline $(8.2 \mathrm{mg})$ was dissolved in aqueous $\mathrm{H}_{2} \mathrm{SO}_{4}$ solution $(0.8 \mathrm{M}, 400 \mathrm{~mL})$ at $278 \mathrm{~K}$ and keep stirring for $30 \mathrm{~min}$. A solution of ammonium persulfate $(170.0 \mathrm{~g} / \mathrm{L}, 160 \mathrm{~mL})$ was dropped into the above mixture solution at $278 \mathrm{~K}$ within $20 \mathrm{~min}$, and then keeps stirring at this temperature for another $40 \mathrm{~min}$. The resulting precipitate (i.e., the sulfate of PAN) was separated by filtration, washed with water $(100 \mathrm{~mL} \times 4)$, and then dried at $353 \mathrm{~K}$ for $10 \mathrm{~h}$. The PAN sulfate $(2.0 \mathrm{~g})$ was then dissolved in aqueous ammonia $(40 \mathrm{~mL})$ and the mixture was stirred at room temperature for $2 \mathrm{~h}$. After the reaction, the solid was filtrated, washed with water $(100 \mathrm{~mL} \times 4)$, and then dried at $353 \mathrm{~K}$ for $10 \mathrm{~h}$. To obtain the $\mathrm{F}_{\mathrm{y}}$-PAN support, the PAN sulfate $(0.2 \mathrm{~g})$ was dissolved 
in aqueous formaldehyde solution (15 40 wt.\%, $8 \sim 15 \mathrm{~mL}$ ), followed by being heated to $413 \mathrm{~K}$ and kept stirring for $2 \mathrm{~h}$. After the completion of the reaction, the solid was filtrated, washed with water $(20 \mathrm{~mL}$ $\times 3$ ), and then dried at $353 \mathrm{~K}$ for $10 \mathrm{~h}$.

$x$-PMo $\mathrm{PM}_{12} / \mathrm{PAN}$ and $x$-PMo $\mathrm{PM}_{12} / \mathrm{F}_{\mathrm{y}}-\mathrm{PAN}$ catalyst were prepared by impregnating PAN or $\mathrm{F}_{\mathrm{y}}$-PAN in aqueous ethanol solution $\left(V_{\mathrm{C}_{2} \mathrm{H}_{5} \mathrm{OH}} / V_{\mathrm{H}_{2} \mathrm{O}}=1 / 1\right)$ containing $\mathrm{PMo}_{12} \mathrm{HPA}$, wherein $x$ (10 50) represented the theoretical mass ratio between HPA and (PAN+HPA) used. In a typical synthesis of 40-PMo $\mathrm{Po}_{12} / \mathrm{PAN}$ catalyst, PAN $(0.24 \mathrm{~g})$ was dissolved in the $\mathrm{PMo}_{12} \mathrm{HPA}$ solution $(4.0 \mathrm{~g} / \mathrm{L}, 40 \mathrm{~mL})$ and the mixture was stirred at room temperature for $12 \mathrm{~h}$. After the reaction, the as-prepared solid was filtrated, washed water $(10 \mathrm{~mL} \times 3)$, and was dried at $353 \mathrm{~K}$ for $10 \mathrm{~h}$.

\subsubsection{Catalyst Characterization}

The FTIR spectra were recorded by a Nicolet Nexus 6700 spectrometer (Boston, MA, USA) with a spectral resolution of $4 \mathrm{~cm}^{-1}$ in the wavenumber range of $500 \sim 4000 \mathrm{~cm}^{-1}$ at room temperature. The XRD patterns were collected by a PANayltical Empyrean powder X-ray diffraction instrument (Almelo, Netherlands) operating at $40 \mathrm{kV}$ and $25 \mathrm{~mA}$ with nickel-filtered $\mathrm{CuK}_{\alpha}$ radiation $(\lambda=1.54056 \AA)$, wherein the data of $2 \theta=5 \sim 50^{\circ}$ with a step of $0.0544^{\circ}$ were recorded. The ICP-AES were conducted on a VG PQExCell instrument (TJA, Boston, MA, USA). The TEM images were obtained on an FEI Tecnai G2 20 TWIN instrument (Hillsboro, OR, USA) at an acceleration voltage of $200 \mathrm{kV}$. The SEM/EDX-mapping images were obtained through a SU3500 Scanning Electron Microscope instrument (HITACHI, Tokyo, Japan), wherein the samples were coated with gold prior to observation. The TG/DTG analysis was conducted on a METTLER TOLEDO TGA/DSC2/1600 instrument (Zurich, Switzerlant) operating at $50 \mathrm{~mL} / \mathrm{min} \mathrm{N}_{2}$ with a heating rate of $10 \mathrm{~K} / \mathrm{min}$ from 313 to $873 \mathrm{~K}$.

\subsubsection{Catalytic Reaction}

All the "one-pot" and "one-step" conversion of fructose to DFF were carried in a $5 \mathrm{~mL}$ round-bottom flask heated in a temperature-controlled oil bath with magnetic stirring. In a typical catalytic reaction, fructose $(45 \mathrm{mg}, 0.25 \mathrm{mmol}), x-\mathrm{PMo}_{12} / \mathrm{PAN}$ or $x-\mathrm{PMo}_{12} / \mathrm{F}_{\mathrm{y}}-\mathrm{PAN}$ catalyst $(30 \mathrm{mg})$, and DMSO $(1 \mathrm{~mL})$ were added into the flask. The mixture was heated to $433 \mathrm{~K}$ and incubated at this temperature for $4 \mathrm{~h}$ in open air with continuous stirring $(400 \mathrm{rpm})$ under reflux. After the reaction, the reaction mixture was cooled gradually to room temperature. The solid catalyst was then isolated from the mixture by centrifugation. The used catalyst was washed with DMSO $(2 \mathrm{~mL} \times 6)$ until the filtrate became transparent, dried at $353 \mathrm{~K}$ for $10 \mathrm{~h}$, and used for the recycling experiments. The top residual mixture after the centrifugation and the washing DMSO were combined and ready to be analyzed. For the aerobic oxidation of HMF to DFF, $35 \mathrm{mg}$ HMF ( $35 \mathrm{mg}, 0.28 \mathrm{mmol}$ ) was used as the substrate while keeping other reaction conditions unchanged ( $30 \mathrm{mg}$ catalyst, $1 \mathrm{~mL} \mathrm{DMSO}, 433 \mathrm{~K}, 4 \mathrm{~h}$, in air).

\subsubsection{Product Analysis}

The quantitative analysis of HMF and DFF was performed on GC (FILI, GC-9790) with an Innowax capillary column $(30 \mathrm{~m} \times 0.25 \mathrm{~mm})$, a hydrogen flame-ionization detector (FID), and a ZB-2020 integrator. The temperature of the injector and detector on GC was $543 \mathrm{~K}$, and benzyl alcohol was used as the internal standard substance. The quantification of FA, LA, FF, etc. was done with an external standard method performing on HPLC (Waters, e2695) with a Bio-Rad Aminex HPX-87 column, a parallax detector, and an ultraviolet detector. The temperatures of the parallax detector and column were 308 and $323 \mathrm{~K}$, respectively. $\mathrm{H}_{2} \mathrm{SO}_{4}(5 \mathrm{mM})$ was applied as a mobile phase with a flow rate of $0.6 \mathrm{~mL} / \mathrm{min}$. The conversion and yields are as defined as follows:

Conversion of substrate $(\mathrm{mol} \%)=(\mathrm{mol}$ of starting substrate-mol of residual substrate $) /(\mathrm{mol}$ of starting substrate) $\times 100 \%$

Yield of HMF $=(\mathrm{mol}$ of HMF produced $) /($ mol of starting fructose $) \times 100 \%$

Yield of DFF $=(\mathrm{mol}$ of DFF produced $) /($ mol of starting substrate $) \times 100 \%$

Yield of FA $=(\mathrm{mol}$ of FA produced $) /(\mathrm{mol}$ of starting substrate $) \times 100 \%$ 
Yield of LA $=($ mol of LA produced $) /($ mol of starting substrate $) \times 100 \%$

\section{Conclusions}

In summary, we report the preparation of bifunctional inorganic-organic hybrid catalysts by supporting keggin-type $\mathrm{PMo}_{12}$ HPA on PAN or F-PAN for the "one-pot" and "one-step" synthesis of DFF from fructose. We show that the $\mathrm{PMo}_{12} \mathrm{HPA}$ is anchored and well-dispersed on the polymer support via site-to-site acid-base interaction between the protons in HPA and the quinoid diimine in PAN, which decreases the Brønsted acidity of the hybrid catalyst while retaining the redox sites of $\mathrm{PMo}_{12} \mathrm{HPA}$. The $x-\mathrm{PMo}_{12} / \mathrm{PAN}$ catalysts $(x=10 \sim 50)$ are active for both HMF-to-DFF oxidation and "one-pot" fructose-to-DFF conversion, however, less stable. Notably, we demonstrate that the grafting of the "support" PAN with formyl groups strengthens the dehydration performance of the 40-PMo $\mathrm{P}_{12} / \mathrm{F}-\mathrm{PAN}$ catalyst, thereby avoiding the negative influence of water and promoting the tandem fructose-to-DFF transformation. The F-PAN acts as a "support" for anchoring and dispersing $\mathrm{PMo}_{12}$ species as well as a co-catalyst for reinforcing the dehydration performance of the $\mathrm{PMo}_{12} / \mathrm{F}-\mathrm{PAN}$ catalyst. A highest DFF yield of $76.7 \%$ has been obtained by conducting the "one-pot" and "one-step" conversion over the $40-\mathrm{PMo}_{12} / \mathrm{F}_{3}-\mathrm{PAN}$ catalyst at $433 \mathrm{~K}$ for $7 \mathrm{~h}$ in air. The alleviation of side-product generations and shortened reaction time lower the production energy for fructose-to-DFF conversion. In addition, the $40-\mathrm{PMo}_{12} / \mathrm{F}_{3}$-PAN catalyst shows good reusability for the fructose-to-DFF conversion, which highlights the designing of novel and stable hybrid inorganic-organic hybrid catalysts for producing important platform furan chemicals from biomass-derived hexose.

Supplementary Materials: The following are available online at http://www.mdpi.com/2073-4344/9/5/445/s1, Figure S1: (a) FTIR spectrum and (b) XRD pattern of Keggin-type PMo 12 $_{2}$ HPA, Figure S2: TEM images of (a) PAN, and (b) 40-PMo ${ }_{12} / \mathrm{PAN}$, Figure S3: FTIR spectra of 40-PMo $\mathrm{PM}_{12} / \mathrm{PAN}$ catalysts after reacting with different substances, Figure S4: TEM images of (a) $\mathrm{F}_{3}-\mathrm{PAN}$, and (b) 40-PMo $12 / \mathrm{F}_{3}-\mathrm{PAN}$, Figure S5: TG and DTG profiles of (a) fresh and (b) spent $40-\mathrm{PMo}_{12} / \mathrm{F}_{3}$-PAN catalysts, Scheme S1: Schematic illustration of the grafting of formyl groups on PAN support, Table S1: Preparation conditions of Fy-PAN "supports" and the results resoluted from the FTIR spectra of $\mathrm{F}_{\mathrm{y}}-\mathrm{PAN}$ and $40-\mathrm{PMo}_{12} / \mathrm{F}_{\mathrm{y}}-\mathrm{PAN}$, Table S2: Comparison of the production rates of several hybrid catalysts in the "one-pot" and "one-step" conversion of fructose to DFF, Table S3: The leaching of $\mathrm{PMo}_{12} \mathrm{HPA}$ during the recycled use of 40-PMo $\mathrm{PM}_{12} / \mathrm{F}_{3}-\mathrm{PAN}$, Table S4: Recycled use of 40-PMo $\mathrm{PM}_{2} / \mathrm{F}_{3}-\mathrm{PAN}$ catalyst in the "one-pot" and "one-step" conversion of fructose to DFF.

Author Contributions: Conceptualization, L.Z. and C.H.; methodology, S.L., J.D. and Z.L.; formal analysis, X.F.; investigation, S.L.; resources, L.Z. and C.H.; data curation, S.L.; writing- original draft preparation, S.L.; writingreview and editing, L.Z. and C.H.; supervision, L.Z. and C.H.; funding acquisition, L.Z. and C.H.

Funding: This research was funded by the Natural Science Foundation of China (No. 21875149), 111 Project (B17030) and the Basal Research Fund of the Central University (2016SCU04B06).

Acknowledgments: We thank Shaolan Wang, Xiaohong Zhu, and Yong Luo in the analytical and testing center of Sichuan University for the TGA, FTIR, and TEM experiments.

Conflicts of Interest: The authors declare no conflict of interest.

\section{References}

1. Tuck, C.O.; Perez, E.; Horvath, I.T.; Sheldon, R.A.; Poliakoff, M. Valorization of Biomass: Deriving More Value from Waste. Science 2012, 337, 695-699. [CrossRef]

2. Liu, B.; Zhang, Z. Catalytic Conversion of Biomass into Chemicals and Fuels over Magnetic Catalysts. ACS Catal. 2016, 6, 326-338. [CrossRef]

3. Arevalo-Gallegos, A.; Ahmad, Z.; Asgher, M.; Parra-Saldivar, R.; Iqbal, H.M.N. Lignocellulose: A sustainable material to produce value-added products with a zero waste approach-A review. Int. J. Biol. Macromol. 2017, 99, 308-318. [CrossRef]

4. Lynd, L.R.; Liang, X.; Biddy, M.J.; Allee, A.; Cai, H.; Foust, T.; Himmel, M.E.; Laser, M.S.; Wang, M.; Wyman, C.E. Cellulosic ethanol: status and innovation. Curr. Opin. Biotechnol. 2017, 45, 202-211. [CrossRef] [PubMed]

5. Bender, T.A.; Dabrowski, J.A.; Gagne, M.R. Homogeneous catalysis for the production of low-volume, high-value chemicals from biomass. Nat. Rev. Chem. 2018, 2, 35-46. [CrossRef] 
6. Hu, L.; Lin, L.; Wu, Z.; Zhou, S.; Liu, S. Recent advances in catalytic transformation of biomass-derived 5-hydroxymethylfurfural into the innovative fuels and chemicals. Renew. Sustain. Energy Rev. 2017, 74, $230-257$. [CrossRef]

7. Kong, X.; Zhu, Y.; Fang, Z.; Kozinski, J.A.; Butler, I.S.; Xu, L.; Song, H.; Wei, X. Catalytic conversion of 5-hydroxymethylfurfural to some value-added derivatives. Green Chem. 2018, 20, 3657-3682. [CrossRef]

8. Yadav, G.D.; Sharma, R.V. Biomass derived chemicals: Environmentally benign process for oxidation of 5-hydroxymethylfurfural to 2,5-diformylfuran by using nano-fibrous Ag-OMS-2-catalyst. Appl. Catal. B-Envion. 2014, 147, 293-301. [CrossRef]

9. Jia, X.; Ma, J.; Wang, M.; Du, Z.; Lu, F.; Wang, F.; Xu, J. Promoted role of $\mathrm{Cu}\left(\mathrm{NO}_{3}\right)_{2}$ on aerobic oxidation of 5-hydroxymethylfurfural to 2,5-diformylfuran over $\mathrm{VOSO}_{4}$. Appl. Catal. A-Gen. 2014, 482, 231-236. [CrossRef]

10. Nie, J.; Liu, H. Efficient aerobic oxidation of 5-hydroxymethylfurfural to 2,5-diformylfuran on manganese oxide catalysts. J. Catal. 2014, 316, 57-66. [CrossRef]

11. Chen, J.; Zhong, J.; Guo, Y.; Chen, L. Ruthenium complex immobilized on poly(4-vinylpyridine)-functionalized carbon-nanotube for selective aerobic oxidation of 5-hydroxymethylfurfural to 2,5-diformylfuran. RSC Adv. 2015, 5, 5933-5940. [CrossRef]

12. Fang, R.; Luque, R.; Li, Y. Selective aerobic oxidation of biomass-derived HMF to 2,5-diformylfuran using a MOF-derived magnetic hollow Fe-Co nanocatalyst. Green Chem. 2016, 18, 3152-3157. [CrossRef]

13. Chatterjee, M.; Ishizaka, T.; Chatterjee, A.; Kawanami, H. Dehydrogenation of 5-hydroxymethylfurfural to diformylfuran in compressed carbon dioxide: an oxidant free approach. Green Chem. 2017, 19, 1315-1326. [CrossRef]

14. Yan, Y.; Li, K.; Zhao, J.; Cai, W.; Yang, Y.; Lee, J.-M. Nanobelt-arrayed vanadium oxide hierarchical microspheres as catalysts for selective oxidation of 5-hydroxymethylfurfural toward 2,5-diformylfuran. Appl. Catal. B-Envion. 2017, 207, 358-365. [CrossRef]

15. Yan, S.; Li, Y.; Li, P.; Jia, T.; Wang, S.; Wang, X. Fabrication of mesoporous $\mathrm{POMs} / \mathrm{SiO}_{2}$ nanofibers through electrospinning for oxidative conversion of biomass by $\mathrm{H}_{2} \mathrm{O}_{2}$ and oxygen. RSC Adv. 2018, 8, 3499-3511. [CrossRef]

16. Ren, Y.; Yuan, Z.; Lv, K.; Sun, J.; Zhang, Z.; Chi, Q. Selective and metal-free oxidation of biomass-derived 5-hydroxymethylfurfural to 2,5-diformylfuran over nitrogen-doped carbon materials. Green Chem. 2018, 20, 4946-4956. [CrossRef]

17. Yuan, Z.; Liu, B.; Zhou, P.; Zhang, Z.; Chi, Q. Aerobic oxidation of biomass-derived 5-hydroxymethylfurfural to 2,5-diformylfuran with cesium-doped manganese dioxide. Catal. Sci. Technol. 2018, 8, 4430-4439. [CrossRef]

18. Zhao, J.; Chen, X.; Du, Y.; Yang, Y.; Lee, J.-M. Vanadium-embedded mesoporous carbon microspheres as effective catalysts for selective aerobic oxidation of 5-hydroxymethyl-2-furfural into 2, 5-diformylfuran. Appl. Catal. A-Gen. 2018, 568, 16-22. [CrossRef]

19. Zhang, Z.; Yuan, Z.; Tang, D.; Ren, Y.; Lv, K.; Liu, B. Iron Oxide Encapsulated by Ruthenium Hydroxyapatite as Heterogeneous Catalyst for the Synthesis of 2,5-Diformylfuran. ChemSusChem 2014, 7, 3496-3504. [CrossRef]

20. Xu, F.; Zhang, Z. Polyaniline-Grafted VO(acac) $)_{2}$ : An Effective Catalyst for the Synthesis of 2,5-Diformylfuran from 5-Hydroxymethylfurfural and Fructose. ChemCatChem 2015, 7, 1470-1477. [CrossRef]

21. Hou, W.; Wang, Q.; Guo, Z.; Li, J.; Zhou, Y.; Wang, J. Nanobelt alpha- $\mathrm{CuV}_{2} \mathrm{O}_{6}$ with hydrophilic mesoporous poly(ionic liquid): a binary catalyst for synthesis of 2,5-diformylfuran from fructose. Catal. Sci. Technol. 2017, 7, 1006-1016. [CrossRef]

22. Liu, Y.; Zhu, L.; Tang, J.; Liu, M.; Cheng, R.; Hu, C. One-pot, One-step Synthesis of 2,5-Diformylfuran from Carbohydrates over Mo-Containing Keggin Heteropolyacids. ChemSusChem 2014, 7, 3541-3547. [CrossRef] [PubMed]

23. Liu, R.; Chen, J.; Chen, L.; Guo, Y.; Zhong, J. One-Step Approach to 2,5-Diformylfuran from Fructose by Using a Bifunctional and Recyclable Acidic Polyoxometalate Catalyst. ChemPlusChem 2014, 79, 1448-1454. [CrossRef]

24. Lv, G.; Wang, H.; Yang, Y.; Deng, T.; Chen, C.; Zhu, Y.; Hou, X. Direct synthesis of 2,5-diformylfuran from fructose with graphene oxide as a bifunctional and metal-free catalyst. Green Chem. 2016, 18, 2302-2307. [CrossRef] 
25. Rathod, P.V.; Nale, S.D.; Jadhav, V.H. Metal Free Acid Base Catalyst in the Selective Synthesis of 2,5-Diformylfuran from Hydroxynnethylfurfural, Fructose, and Glucose. ACS Sustain. Chem. Eng. 2017, 5, 701-707. [CrossRef]

26. Yang, Z.; Qi, W.; Su, R.; He, Z. 3D Flower-like Micro/Nano Ce-Mo Composite Oxides as Effective Bifunctional Catalysts for One-Pot Conversion of Fructose to 2,5-Diformylfuran. ACS Sustain. Chem. Eng. 2017, 5, 4179-4187. [CrossRef]

27. Zhao, J.; Jayakumar, A.; Hu, Z.-T.; Yan, Y.; Yang, Y.; Lee, J.-M. $\mathrm{MoO}_{3}$-Containing Protonated Nitrogen Doped Carbon as a Bifunctional Catalyst for One-Step Synthesis of 2,5-Diformylfuran from Fructose. ACS Sustain. Chem. Eng. 2018, 6, 284-291. [CrossRef]

28. Zhao, J.; Jayakumar, A.; Lee, J.-M. Bifunctional Sulfonated $\mathrm{MoO}_{3}-\mathrm{ZrO}_{2}$ Binary Oxide Catalysts for the One-Step Synthesis of 2,5-Diformylfuran from Fructose. ACS Sustain. Chem. Eng. 2018, 6, $2976-2982$. [CrossRef]

29. Zhang, W.; Meng, T.; Tang, J.; Zhuang, W.; Zhou, Y.; Wang, J. Direct Synthesis of 2,5-Diformylfuran from Carbohydrates Using High-Silica MOR Zeolite-Supported Isolated Vanadium Species. ACS Sustain. Chem. Eng. 2017, 5, 10029-10037. [CrossRef]

30. Chen, J.; Guo, Y.; Chen, J.; Song, L.; Chen, L. One-Step Approach to 2,5-Diformylfuran from Fructose by Proton-and Vanadium-Containing Graphitic Carbon Nitride. ChemCatChem 2014, 6, 3174-3181. [CrossRef]

31. Fang, R.; Luque, R.; Li, Y. Efficient one-pot fructose to DFF conversion using sulfonated magnetically separable MOF-derived $\mathrm{Fe}_{3} \mathrm{O}_{4}$ (111) catalysts. Green Chem. 2017, 19, 647-655. [CrossRef]

32. Mittal, N.; Nisola, G.M.; Malihan, L.B.; Seo, J.G.; Kim, H.; Lee, S.-P.; Chung, W.-J. One-pot synthesis of 2,5-diformylfuran from fructose using a magnetic bi-functional catalyst. RSC Adv. 2016, 6, 25678-25688. [CrossRef]

33. Sarmah, B.; Satpati, B.; Srivastava, R. One-pot tandem conversion of monosaccharides and disaccharides to 2,5-diformylfuran using a Ru nanoparticle-supported H-beta catalyst. Catal. Sci. Technol. 2018, 8, $2870-2882$. [CrossRef]

34. Ma, B.; Wang, Y.; Guo, X.; Tong, X.; Liu, C.; Wang, Y.; Guo, X. Photocatalytic synthesis of 2,5-diformylfuran from 5-hydroxymethyfurfural or fructose over bimetallic $\mathrm{Au}-\mathrm{Ru}$ nanoparticles supported on reduced graphene oxides. Appl. Catal. A-Gen. 2018, 552, 70-76. [CrossRef]

35. Raut, A.B.; Bhanage, B.M. Co-Al Hydrotalcites: Highly Active Catalysts for the One-Pot Conversion of Fructose to 2,5-Diformylfuran. Chemistryselect 2018, 3, 11388-11397. [CrossRef]

36. Wang, Z.M.; Liu, L.-J.L.; Xiang, B.; Wang, Y.; Lyu, Y.J.; Qi, T.; Si, Z.B.; Yang, H.Q.; Hu, C.W. The design and catalytic performance of molybdenum active sites on an MCM-41 framework for the aerobic oxidation of 5-hydroxymethylfurfural to 2,5-diformylfuran. Catal. Sci. Technol. 2019, 9, 811-821. [CrossRef]

37. Gu, B.; He, S.; Zhou, W.; Kang, J.; Cheng, K.; Zhang, Q.; Wang, Y. Polyaniline-supported iron catalyst for selective synthesis of lower olefins from syngas. J. Energy Chem. 2017, 26, 608-615. [CrossRef]

38. Patel, H.A.; Sawant, A.M.; Rao, V.J.; Patel, A.L.; Bedekar, A.V. Polyaniline Supported $\mathrm{FeCl}_{3}$ : An Effective Heterogeneous Catalyst for Biginelli Reaction. Catal. Lett. 2017, 147, 2306-2312. [CrossRef]

39. Samai, B.; Bhattacharya, S.C. Conducting polymer supported cerium oxide nanoparticle: Enhanced photocatalytic activity for waste water treatment. Mater. Chem. Phys. 2018, 220, 171-181. [CrossRef]

40. Jesus Garcia-Fernandez, M.; Mercedes Pastor-Blas, M.; Epron, F.; Sepulveda-Escribano, A. Proposed mechanisms for the removal of nitrate from water by platinum catalysts supported on polyaniline and polypyrrole. Appl. Catal. B-Envion. 2018, 225, 162-171. [CrossRef]

41. Das, S.; Dutta, K.; Kundu, P.P.; Bhattacharya, S.K. Nanostructured Polyaniline: An Efficient Support Matrix for Platinum-Ruthenium Anode Catalyst in Direct Methanol Fuel Cell. Fuel Cells 2018, 18, 369-378. [CrossRef]

42. Liu, Y.; Tang, D.; Cao, K.; Yu, L.; Han, J.; Xu, Q. Probing the support effect at the molecular level in the polyaniline-supported palladium nanoparticle-catalyzed Ullmann reaction of aryl iodides. J. Catal. 2018, 360, 250-260. [CrossRef]

43. Tanwar, R.; Kaur, B.; Mandal, U.K. Highly efficient and visible light driven Ni0.5Zn0.5Fe ${ }_{2} \mathrm{O}_{4} @ P A N I$ modified $\mathrm{BiOCl}$ heterocomposite catalyst for water remediation. Appl. Catal. B-Envion. 2017, 211, 305-322. [CrossRef]

44. Gallon, B.J.; Kojima, R.W.; Kaner, R.B.; Diaconescu, P.L. Palladium nanoparticles supported on polyaniline nanofibers as a semi-heterogeneous catalyst in water. Angew. Chem. Int. Ed. 2007, 46, 7251-7254. [CrossRef]

45. Zhu, L.; Dai, J.; Liu, M.; Tang, D.; Liu, S.; Hu, C. Formyl-Modified Polyaniline for the Catalytic Dehydration of Fructose to 5-Hydroxymethylfurfural. ChemSusChem 2016, 9, 2174-2181. [CrossRef] 
46. Dai, J.; Zhu, L.; Tang, D.; Fu, X.; Tang, J.; Guo, X.; Hu, C. Sulfonated polyaniline as a solid organocatalyst for dehydration of fructose into 5-hydroxymethylfurfural. Green Chem. 2017, 19, 1932-1939. [CrossRef]

47. Dai, J.; Liu, Z.; Hu, Y.; Liu, S.; Chen, L.; Qi, T.; Yang, H.; Zhu, L.; Hu, C. Adjusting the acidity of sulfonated organocatalyst for the one-pot production of 5-ethoxymethylfurfural from fructose. Catal. Sci. Technol. 2019, 9, 483-492. [CrossRef]

48. Tsigdinos, G.A.; Hallada, C.J. Molybdovanadophosphoric Acids and Their Salts. I. Investigation of Methods of Preparation and Characterization. Inorg. Chem. 1968, 7, 437-441. [CrossRef]

49. Nandi, M.; Gangopadhyay, R.; Bhaumik, A. Mesoporous polyaniline having high conductivity at room temperature. Microporous Mesoporous Mater. 2008, 109, 239-247. [CrossRef]

50. Thiemann, C.; Brett, C.M.A. Electropolymerisation and properties of conducting polymers derived from aminobenzenesulphonic acids and from mixtures with aniline. Synth. Met. 2001, 125, 445-451. [CrossRef]

51. Cao, Y.; Li, S.Z.; Xue, Z.J.; Guo, D. Spectroscopic and electrical characterization of some aniline oligomers and polyaniline. Synth. Met. 1986, 16, 305-315. [CrossRef]

52. Kang, E.T.; Neoh, K.G.; Tan, K.L. Polyaniline: A polymer with many interesting intrinsic redox states. Prog. Polym. Sci. 1998, 23, 277-324. [CrossRef]

53. Trchova, M.; Sedenkova, I.; Konyushenko, E.N.; Stejskal, J.; Holler, P.; Ciric-Marjanovic, G. Evolution of polyaniline nanotubes: The oxidation of aniline in water. J. Phys. Chem. B 2006, 110, 9461-9468. [CrossRef] [PubMed]

54. Furukawa, Y.; Ueda, F.; Hyodo, Y.; Harada, I.; Nakajima, T.; Kawagoe, T. Vibrational-spectra and structure of polyaniline. Macromolecules 1988, 21, 1297-1305. [CrossRef]

55. Xing, S.X.; Zheng, H.W.; Zhao, G.K. Preparation of polyaniline nanofibers via a novel interfacial polymerization method. Synth. Met. 2008, 158, 59-63. [CrossRef]

56. Pouget, J.P.; Jozefowicz, M.E.; Epstein, A.J.; Tang, X.; Macdiarmid, A.G. X-ray structure of polyaniline. Macromolecules 1991, 24, 779-789. [CrossRef]

57. Gong, J.; Hua, R.N.; Xie, Z.W.; Wang, S.G.; Qu, L.Y. Chemical syntheses of the conducting material formed by heteropolyacids and polyaniline. Polym. J. 2001, 33, 377-382. [CrossRef]

58. Xing, S.X.; Zhao, C.; Jing, S.Y.; Wang, Z. Morphology and conductivity of polyaniline nanofibers prepared by 'seeding' polymerization. Polymer 2006, 47, 2305-2313. [CrossRef]

59. Liao, Y.; Strong, V.; Chian, W.; Wang, X.; Li, X.-G.; Kaner, R.B. Sulfonated Polyaniline Nanostructures Synthesized via Rapid Initiated Copolymerization with Controllable Morphology, Size, and Electrical Properties. Macromolecules 2012, 45, 1570-1579. [CrossRef]

60. Papagianni, G.G.; Stergiou, D.V.; Armatas, G.S.; Kanatzidis, M.G.; Prodromidis, M.I. Synthesis, characterization and performance of polyaniline-polyoxometalates $\left(\mathrm{XM}_{12}, \mathrm{X}=\mathrm{P}, \mathrm{Si}\right.$ and $\left.\mathrm{M}=\mathrm{Mo}, \mathrm{W}\right)$ composites as electrocatalysts of bromates. Sens. Actuators B 2012, 173, 346-353. [CrossRef]

61. Cui, J.; Tan, J.; Deng, T.; Cui, X.; Zhu, Y.; Li, Y. Conversion of carbohydrates to furfural via selective cleavage of the carbon-carbon bond: the cooperative effects of zeolite and solvent. Green Chem. 2016, 18, 1619-1624. [CrossRef]

62. Wang, Y.Q.; Yang, X.H.; Zheng, H.Y.; Li, X.Q.; Zhu, Y.L.; Li, Y.W. Mechanistic insights on catalytic conversion fructose to furfural on beta zeolite via selective carbon-carbon bond cleavage. Mol. Catal. 2019, 463, 130-139. [CrossRef]

(C) 2019 by the authors. Licensee MDPI, Basel, Switzerland. This article is an open access article distributed under the terms and conditions of the Creative Commons Attribution (CC BY) license (http://creativecommons.org/licenses/by/4.0/). 